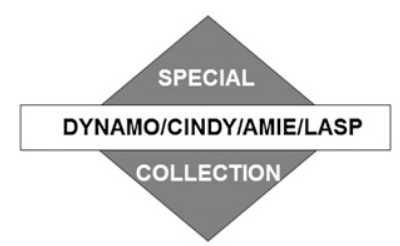

\title{
Diurnal Forcing and Phase Locking of Gravity Waves in the Maritime Continent ${ }^{\mathscr{O}}$
}

\author{
JAMES H. RUPPERT JR. AND FUQING ZHANG \\ Department of Meteorology and Atmospheric Science, and Center for Advanced Data Assimilation and \\ Predictability Techniques, The Pennsylvania State University, University Park, Pennsylvania
}

(Manuscript received 10 March 2019, in final form 21 June 2019)

\begin{abstract}
An unfiltered zonal Hovmöller depiction of rainfall in the Maritime Continent (MC) reveals remarkable spatiotemporal continuity of zonally propagating disturbances with a diurnal period, which endure over multiple days and propagate faster than the individual convective storms they coupled with. This phenomenon and its sensitivity to the Madden-Julian oscillation (MJO) during the 2011/12 Dynamics of the MJO (DYNAMO) field campaign is examined here through a well-validated, convection-permitting model simulation conducted on a large domain. We find that these disturbances are zonally propagating diurnal gravity waves excited by vigorous nocturnal mesoscale convective systems over Sumatra and Borneo. These gravity waves are diurnally phase locked: their wavelength very closely matches the distance between these two islands $(\sim 1500 \mathrm{~km})$, while their particular zonal phase speed $\left(\sim \pm 17 \mathrm{~m} \mathrm{~s}^{-1}\right)$ allows them to propagate this distance in one diurnal cycle. We therefore hypothesize that these waves are amplified by resonant interaction due to diurnal phase locking. While these zonal gravity waves decouple from convection once beyond the MC, their divergent flow signature endures well across the Indian Ocean, provoking the notion that they may influence rainfall at far remote locations. The exact controls over this zonal phase speed remain uncertain; we note, however, that it is roughly consistent with diurnal offshore-propagating modes documented previously. Further study is required to tie this down, and more generally, to understand the sensitivity of these modes to background flow strength and the geography of the MC.
\end{abstract}

\section{Introduction}

As a dominant source of latent heating, the tropical Maritime Continent (MC) exerts profound influence over global circulation (Ramage 1968; Krishnamurti et al. 1973). The persistence of upward motion here likely owes to its unique abundance of land, sea, and coastline: the resulting combination of moisture availability from a warm sea surface and strong diurnal solenoidal circulations ensures daily thunderstorm activity, and hence strong tropospheric heating in the mean (Dai 2001; Cronin et al. 2015; Yamanaka et al. 2018). Owing to the prevailing importance of local mesoscale circulations in the MC, adequately modeling weather and climate here has been a major longstanding challenge-a

\footnotetext{
Supplemental information related to this paper is available at the Journals Online website: https://doi.org/10.1175/JAS-D-190061.s1.
}

Corresponding author: James H. Ruppert Jr., jruppert.jr@ gmail.com challenge that links to weather prediction across a vast range of space and time scales (Neale and Slingo 2003; Waliser et al. 2003; Dai and Trenberth 2004; Love et al. 2011). Here we seek to address this challenge by investigating diurnal convective systems in the MC; namely, their role in forcing and coupling with long-lived gravity waves.

Among the most dominant drivers of weather variability in the MC is the Madden-Julian oscillation (MJO; Madden and Julian 1972). The MJO is a convectively coupled tropical wave that propagates slowly eastward $\left(\sim 5 \mathrm{~m} \mathrm{~s}^{-1}\right)$ through the Indo-Pacific warm pool region, modulating deep overturning motion and moist convection on intraseasonal time scales (Zhang 2005). Yet since the diurnal cycle is the primary rainfall mechanism in the MC, the intraseasonal rainfall variation due to the MJO manifests to first order in a modulation of diurnal phase and amplitude (Oh et al. 2012; Peatman et al. 2014; Sakaeda et al. 2017). As the MJO advances eastward toward the MC from the central Indian Ocean, rainfall jumps ahead, leading the main envelope by 5-10 days (Oh et al. 2012; Sakaeda et al. 2017). 
The MC experiences strong diurnal insolation during this period, causing a preferential enhancement of the evening rainfall peak over the islands (Ichikawa and Yasunari 2006; Fujita et al. 2011; Rauniyar and Walsh 2011; Sakaeda et al. 2017). With the arrival of the MJO envelope, in contrast, early-morning rainfall over the coastal and offshore regions is enhanced, while the diurnal variation over land is suppressed. A similar projection of diurnal rainfall variation onto the intraseasonal cycle has been documented in coastal South China (Chen et al. 2019).

Yet the interaction between the MC and MJO is very much two-way. In addition to the above impacts on the diurnal cycle, the background humidity state over the $\mathrm{MC}$ is critical to the MJO's propagation, with drier-thannormal background conditions seemingly explaining the failure of many MJO events to propagate across the MC (Feng et al. 2015; Kerns and Chen 2016; Kim et al. 2017; Zhang and Ling 2017; DeMott et al. 2018). The inability of many general circulation models (GCMs) to properly represent the MJO may indeed stem from their inability to represent the basic moisture state over the MC (Gonzalez and Jiang 2017; Jiang 2017). Such model issues have been remarkably enduring (Jiang et al. 2009), which emphasizes our insufficient understanding of how local diurnal processes-the prevailing driver of moist convection in the MC-rectify and interact with largerscale circulation (Peatman et al. 2014; Cronin et al. 2015; Ruppert 2016; Yamanaka et al. 2018). This study seeks a better understanding of this link.

Herein we explore the interaction between diurnally generated rainfall systems in the MC with the large-scale flow, and the influence of the MJO therein. In an unfiltered zonal Hovmöller view, propagating diurnal rainfall disturbances in the MC are remarkably long lived, and take on a prominent eastward or westward phase speed of $\sim 15-20 \mathrm{~m} \mathrm{~s}^{-1}$ (Ichikawa and Yasunari 2007). This phase speed is similar to offshore-propagating disturbances studied previously in the Panama Bight region (Mapes et al. 2003a,b; Warner et al. 2003), the Bay of Bengal (Yang and Slingo 2001; Zuidema 2003), and the South China Sea (Aves and Johnson 2008). While the nocturnal land breeze was originally invoked to explain the offshore propagation of convective systems from Borneo (Houze et al. 1981), subsequent work suggests that gravity waves are critical to explaining both relatively fast phase speeds and long lifetimes (Mapes et al. 2003b; Aves and Johnson 2008; Qian et al. 2009, 2012). Herein we provide further evidence in support of this view. Yet, unique from other regions, the specific geography of the MC may favor a unique phase speed and/or amplify a specific mode; namely, this can occur owing to diurnal phase locking across multiple islands

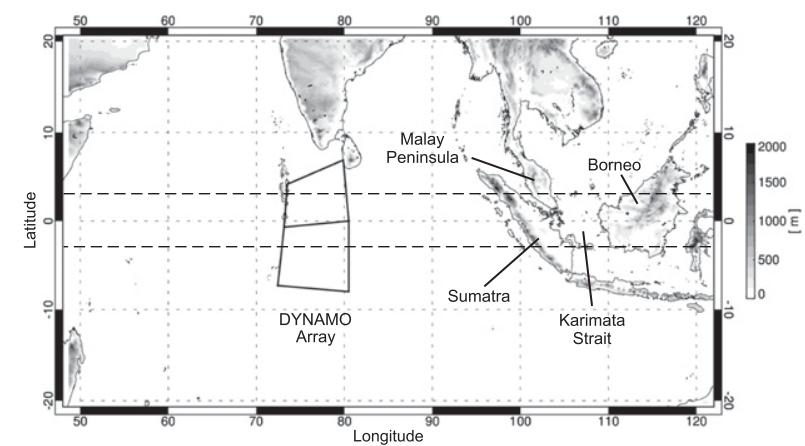

FIG. 1. Map of WRF Model domain (entire region shown), with terrain height (shaded; m). DYNAMO sounding array (double quadrilateral) and pertinent locations are labeled. Heavy dashed lines mark the bounds of zonal cross sections $\left(3^{\circ} \mathrm{S}-3^{\circ} \mathrm{N}\right)$.

and diurnal cycles, as will be described. Given the difficulty of adequately observing such high-frequency modes, to explore this phenomenon herein we exploit an observationally validated cloud-permitting model simulation that explicitly represents both convective processes and the large-scale background flow.

\section{Methodology}

A major international push to both sample and better understand MJO convective initiation culminated in a field experiment from October 2011 to March 2012 (Yoneyama et al. 2013): Cooperative Indian Ocean Experiment on Intraseasonal Variability in the Year 2011 (CINDY2011), Dynamics of the MJO (DYNAMO), and ARM MJO Investigation Experiment (AMIE). This experiment (denoted simply DYNAMO) was conducted in the typical region of MJO convective initiation, the central Indian Ocean, in order to better understand what governs the transition from shallow to deep convection during its initiation (Yoneyama et al. 2013; Powell and Houze 2013, 2015; Johnson et al. 2015; Ruppert and Johnson 2015, 2016; Ruppert 2016; Chen and Zhang 2019). Two robust MJO events were captured by DYNAMO in October and November 2011, both characterized by convective initiation in the Indian Ocean, followed by eastward propagation to the MC (Gottschalck et al. 2013; Johnson and Ciesielski 2013).

This study invokes the large-scale convection-permitting regional model simulation described by Wang et al. (2015), which successfully reproduced the October and November DYNAMO MJO events. The simulation was conducted using the Weather Research and Forecasting (WRF) Model, version 3.4.1 (Skamarock et al. 2008), with the domain shown in Fig. 1, using the European Centre for Medium-Range Weather Forecasts (ECMWF) interim 
reanalysis (ERA-Interim; Dee et al. 2011) to provide initial and boundary conditions. The model grid was discretized with 9-km horizontal spacing, with a stretched vertical grid of 45 vertical levels, with 9 levels within the lowest $1 \mathrm{~km}$. Although this horizontal grid spacing is insufficient for realistically resolving individual cloud elements, it adequately captures the deepconvective scales of overturning motion and their coupling with the MJO (Wang et al. 2015; Zhang et al. 2017; Ying and Zhang 2017; Chen et al. 2018), as well as the mesoscale dynamics important to the diurnal cycle (as will be demonstrated herein). The two-moment WRF microphysics scheme was employed. Sea surface temperature (SST) was updated every $6 \mathrm{~h}$. Noah land surface physics was invoked, with an ocean surface skin temperature parameterization (Zeng and Beljaars 2005) to realistically capture diurnal variations in surface fluxes. Readers are referred to Wang et al. (2015) for additional details.

This study focuses on the period of 1 October16 November, which encompasses the entire October MJO event and distinct diurnal convective regimes within the MC. Three-hourly model output is analyzed. We additionally invoke 3-hourly rainfall from the Tropical Rainfall Measuring Mission (TRMM) 3B42v7 multi-satellite-sensor estimate (Huffman et al. 2007; provided on a $0.25^{\circ} \times 025^{\circ}$ latitude-longitude grid), and hourly reanalysis data from the fifth major global reanalysis produced by ECMWF (ERA5), which is provided on a $0.25^{\circ} \times 025^{\circ}$ grid. These datasets are invoked both for validation of the background state of the model and to compare propagating diurnal disturbances. Much of the analysis is centered on latitudinal averages from $3^{\circ} \mathrm{S}$ to $3^{\circ} \mathrm{N}$. Local standard time (LST) is taken herein to be that for Sumatra and Malaysia $(\mathrm{UTC}+7 \mathrm{~h})$.

\section{Analysis}

A Hovmöller diagram of 3-hourly TRMM rainfall spanning the local lifetime of the October DYNAMO MJO event exhibits a rich spectrum of variability (Fig. 2a). The MJO convective envelope initiates in mid-October over the Indian Ocean around $55^{\circ}-75^{\circ} \mathrm{E}$, and propagates slowly eastward toward the $\mathrm{MC}$ at $\sim 3-5 \mathrm{~m} \mathrm{~s}^{-1}$ (annotated in Fig. 2a). The increase in rainfall during convective initiation roughly coincides with an increase in easterly $850-\mathrm{hPa}$ background zonal flow $U$ over the Indian Ocean and MC ("background" refers to time scales of several days and greater). The value of $U$ is calculated from the zonal wind $u$ filtered with a 5-day running average, with the time mean subtracted. As the convective envelope shifts eastward, so too does a region of convergence in $U$, consistent with the eastward propagation of the zonal Walker-like overturning coupled to MJO convection (Madden and Julian 1972; Kiladis et al. 2005; Gottschalck et al. 2013). The WRF simulation captures this overall evolution of the MJO quite well (Fig. 2b). This simulation and its validation against observations is described in detail by Wang et al. (2015). Further validation is provided herein.

The convection is characterized by pronounced variability at higher frequencies in addition to the intraseasonal evolution. A prominent component of that over the Indian Ocean is due to 2-day waves (Zuluaga and Houze 2013; Yu et al. 2018). Two-day waves have been noted across the Indo-Pacific warm pool region and extensively studied, although their exact cause remains uncertain (Chen and Houze 1997; Takayabu et al. 1996; Haertel and Kiladis 2004).

Yet the most prominent, regular, and coherent signal at high frequency is that due to westward- and eastward-propagating convective disturbances that span the majority of the $\mathrm{MC}$, from $\sim 90^{\circ}$ to $120^{\circ} \mathrm{E}$ (annotated in Fig. 2a). Virtually all of these disturbances are purely diurnal, implying an origin tied to the diurnally forced deep convection in the MC (Ichikawa and Yasunari 2006). These disturbances appear slightly more regularly in WRF than TRMM (e.g., from 1 to 15 October), although there is consistency to first order. The spatiotemporal continuity of rainfall, despite its intermittence, implies that something acts to organize and orchestrate rainfall along these trajectories on a multiday time scale. Evidence provided in the forthcoming analysis indeed suggests that these disturbances are diurnal gravity waves.

The propagation direction of these diurnal convective disturbances varies in nearly perfect correspondence with the direction of $U$, as pointed out by Ichikawa and Yasunari $(2006,2007)$. Namely, the disturbances propagate westward when under prevailing easterly $U$, and eastward under westerly $U$ (Fig. 2). This phenomenon is a climatological feature of diurnal convection in the MC (Ichikawa and Yasunari 2006, 2007; Fujita et al. 2011). To investigate these systems we generate composites over the two propagation regimes through an index of $U$ averaged from $90^{\circ}$ to $121^{\circ} \mathrm{E}$ : days with $U>1 \mathrm{~m} \mathrm{~s}^{-1}$ are denoted westerly and days with $U<-1 \mathrm{~m} \mathrm{~s}^{-1}$ are denoted easterly. The resulting composite regimes are annotated in Fig. 2 (note slight differences in the composite periods between TRMM and WRF). Variables are then averaged either fully across the time dimension for each period, or as a function of hour of the day to generate a composite diurnal cycle. 
(a) TRMM, ERA5

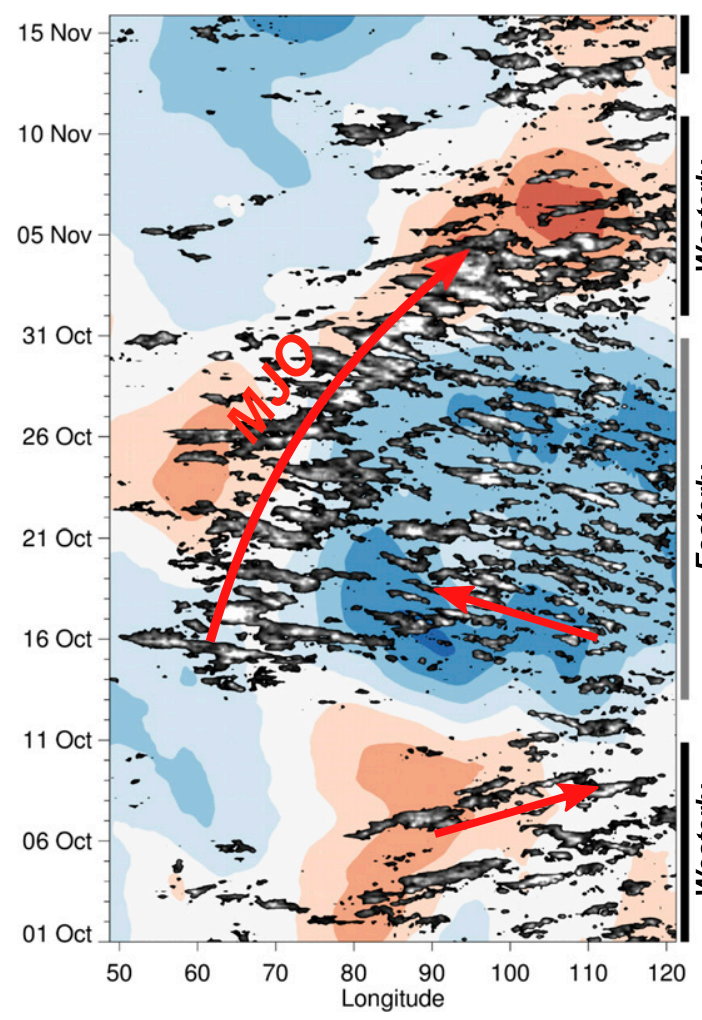

(b) WRF

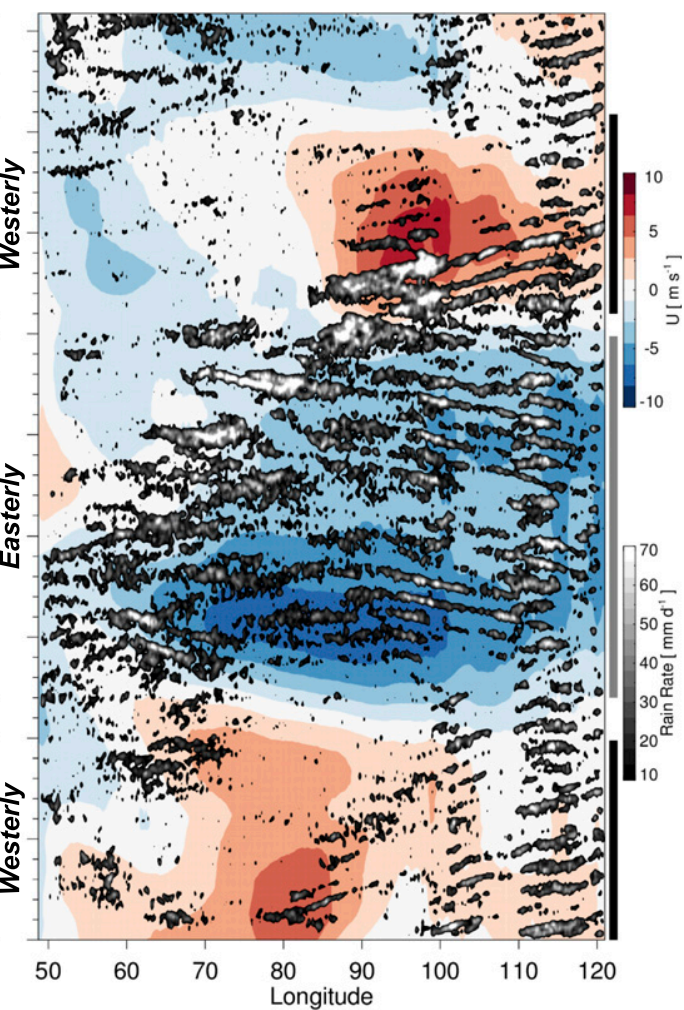

FIG. 2. Time-longitude series for 1 Oct-16 Nov 2011 with 3-hourly rainfall rate (gray shading) and 850-hPa background zonal wind $U$ (color shading) averaged from $3^{\circ} \mathrm{S}$ to $3^{\circ} \mathrm{N}$. (a) TRMM 3B42v7 rainfall and ERA5 wind and (b) WRF simulation [interpolated onto a $0.25^{\circ}$ grid for comparison with (a)]. The value of $U$ is calculated by filtering the zonal wind $u$ with a 5-day running average and subtracting the time mean. Composites in subsequent figures are based on days with westerly $U$ (denoted as the westerly regime; black bars) and easterly $U$ (easterly regime; gray bars) averaged over $90^{\circ}-121^{\circ} \mathrm{E}$. Large red arrow depicts $\mathrm{MJO}$ convective envelope, and two small arrows depict propagating diurnal disturbances.

The mean conditions of these two regimes are quite distinct (Fig. 3). In the easterly regime, there is easterly prevailing flow throughout the column over the MC with weak shear (Figs. 3a,c), compared to the westerly composite, which is characterized by strong easterly wind shear, with westerly flow from the surface to $\sim 500 \mathrm{hPa}$. The easterly regime is predominately influenced by the MJO convectively active phase situated in the central Indian Ocean, while enhanced westerly flow in the lower to midtroposphere in the westerly regime is a consistent with the active phase being situated in or east of the MC (Fig. 2) (Gottschalck et al. 2013). Overall, the flow fields compare very well with ERA5 (Figs. 3a-d), and especially in these primary distinctions between the two regimes. The primary differences are in the easterly composites, which include slightly weaker (stronger) easterly flow at low levels (in the upper troposphere) from $100^{\circ}$ to $120^{\circ} \mathrm{E}$ in $\mathrm{WRF}$, and weaker low-level westerly flow across the western to central Indian Ocean in
WRF. Consistencies between TRMM and WRF described below suggest that these differences are inconsequential for main subject of study.

Consistent with the MJO active phase being situated in or east of the MC during the westerly regime (Gottschalck et al. 2013), the mid- to upper troposphere is indeed more moist over the MC (Figs. 3e,f). It is somewhat counterintuitive that rainfall over the MC prevails during the relatively drier easterly regime, prior to the arrival of the MJO active phase (Fig. 2). This emphasizes the importance of local diurnal solar forcing in the MC, which is argued to explain why rainfall commonly increases approximately a week prior to the arrival of the MJO's moisture envelope (Oh et al. 2012; Peatman et al. 2014; Sakaeda et al. 2017).

The composite diurnal cycles of rainfall for the easterly and westerly regimes are shown through diurnal Hovmöller diagrams in Fig. 4, which include every day of each regime. The composite of the easterly regime exhibits a much higher degree of spatiotemporal continuity 


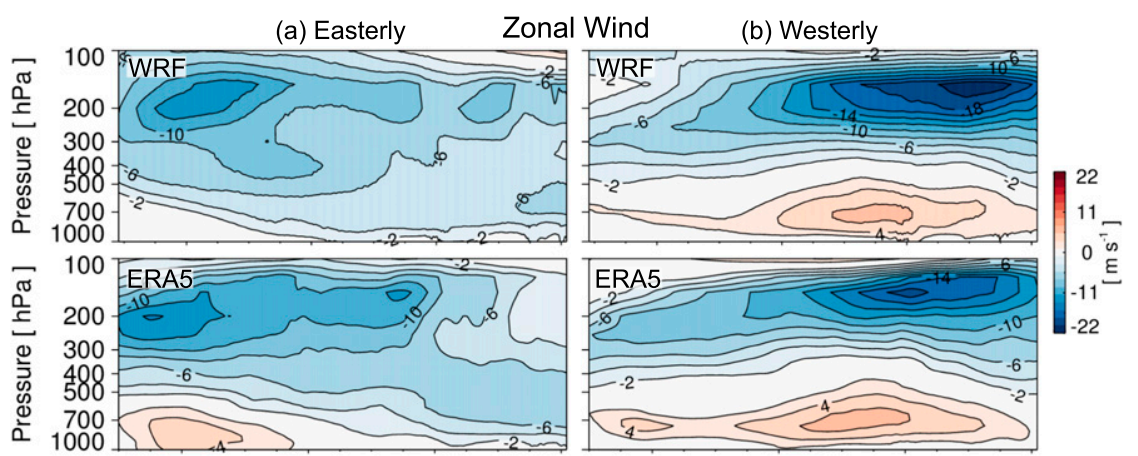

$\begin{array}{lll}\text { (c) Easterly Meridional Wind } \quad \text { (d) Westerly } & \end{array}$
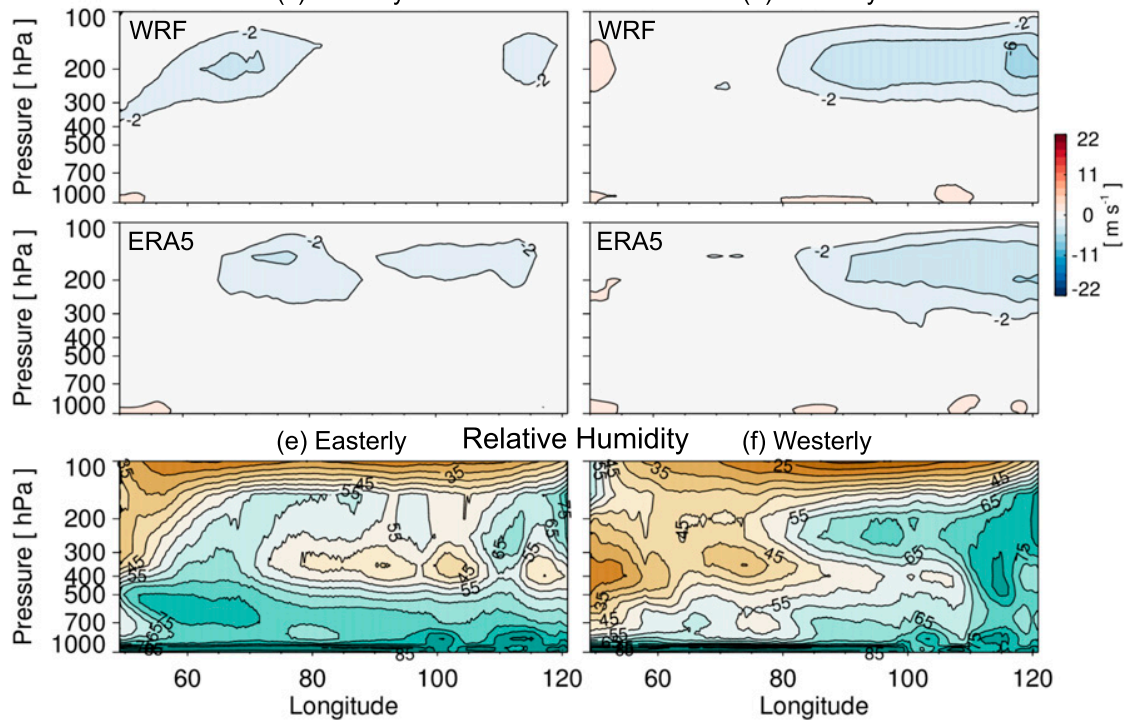

FIG. 3. Zonal cross sections averaged from $3^{\circ} \mathrm{S}$ to $3^{\circ} \mathrm{N}$ with mean (a),(b) $u\left(\mathrm{~m} \mathrm{~s}^{-1}\right)$, (c),(d) meridional wind $v\left(\mathrm{~m} \mathrm{~s}^{-1}\right)$, and (e),(f) relative humidity (\%) for (a),(c),(e) easterly and (b),(d),(f) westerly composites in WRF. For comparison, $u$ and $v$ from ERA5 are included underneath WRF in (a)-(d).

than that in the westerly regime; nevertheless, the distinct propagation direction of the two regimes is evident. Despite the difference in propagation direction, the composite disturbances in both regimes exhibit a zonal wavelength $\lambda_{x} \sim 1400-1500 \mathrm{~km}$ and phase speed $c_{x} \sim$ $\pm 17 \mathrm{~m} \mathrm{~s}^{-1}$. Notice that this wavelength is the approximate zonal distance between Sumatra and Borneo along the equator (Fig. 1). It follows from this match and the phase speed of these propagating modes that they are diurnally phase locked; namely, this particular phase speed allows these modes to propagate this distance in one diurnal cycle. We later explore the hypothesis that this diurnal phase locking leads to a resonant effect that allows the modes to be maintained or amplified by the synchronized diurnal cycles of the two island regions (section 4).

The diurnal anomaly of zonal wind $u^{\prime}$ at $150 \mathrm{hPa}$ in WRF exhibits a highly coherent signal with rainfall, of amplitude $\sim \pm 3 \mathrm{~m} \mathrm{~s}^{-1}$. Peak rainfall is virtually always situated in divergent upper-level flow, implying a tight coupling with deep convection (Figs. 4a,b). Yet $u^{\prime}$ reveals a striking phenomenon: while rainfall exhibits continuity across the $\mathrm{MC}$, from $\sim 115^{\circ}$ to $90^{\circ} \mathrm{E}(\sim 3000 \mathrm{~km})$, the $u^{\prime}$ signal arguably continues beyond $60^{\circ} \mathrm{E}(\sim 5000 \mathrm{~km})$ in the easterly regime, although it weakens and potentially deforms in the absence of rainfall coupling. There may, in fact, be recoupling of this $u^{\prime}$ signal with rainfall from $\sim 60^{\circ}$ to $75^{\circ} \mathrm{E}$ in WRF, though this is less conclusive. The lifetime of these disturbances is estimated to be $T \sim 2-3.5$ days based on either the rainfall or $u^{\prime}$ signals in Fig. 4a. Although the inferred speed for westerly is in a similar range, it is less clear because of its more discontinuous nature (Fig. 4b).

There is remarkable, broad consistency between the simulated rainfall propagation in WRF with that in TRMM, both in terms of phase and amplitude (Figs. 4c,d). Such a match is extremely difficult for models to achieve, especially when convection is parameterized 
(a) Easterly

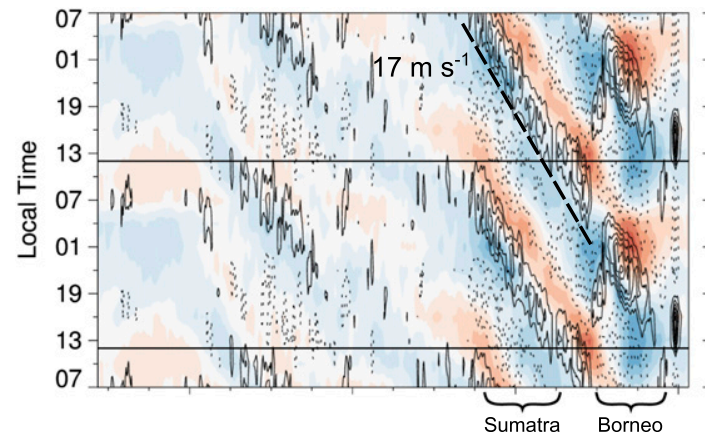

(c) Easterly

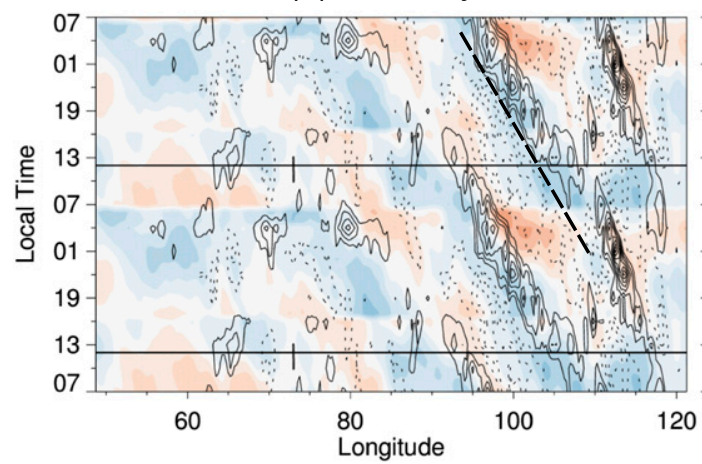

WRF

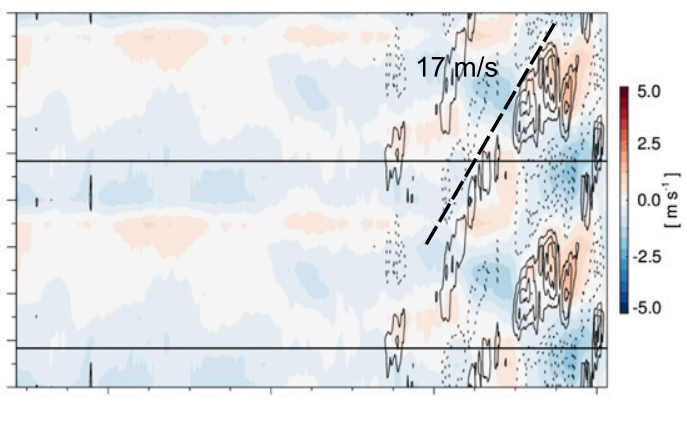

(d) Westerly

(b) Westerly

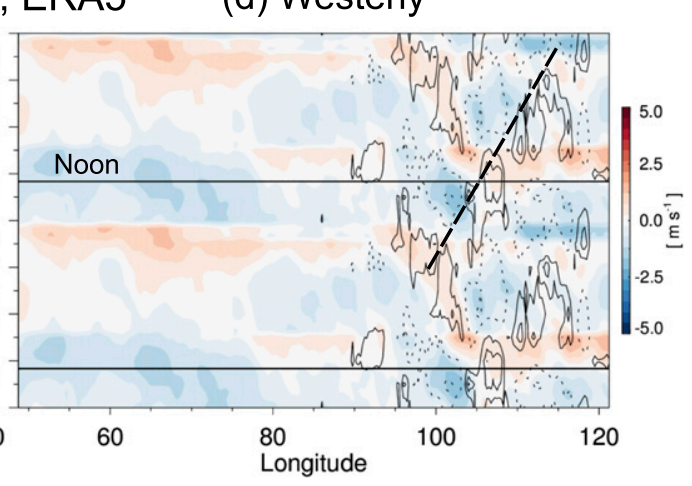

FIG. 4. Diurnal composite time-longitude series averaged from $3^{\circ} \mathrm{S}$ to $3^{\circ} \mathrm{N}$ (repeated in time for continuity), with rainfall with the time mean subtracted (contoured every $4 \mathrm{~mm} \mathrm{day}^{-1}$, zero contour omitted) and $u$ at $150 \mathrm{hPa}$ with time mean subtracted $u^{\prime}$ (shading) for the (a), (c) easterly and (b), (d) westerly composites (see Fig. 2b for composite days) from (a),(b) WRF and (c),(d) TRMM, ERA5. Phase speed of $\pm 17 \mathrm{~m} \mathrm{~s}^{-1}$ is indicated (dashed lines). LST corresponds to that for Sumatra and Malaysia (UTC $+7 \mathrm{~h}$ ) here and in subsequent figures.

(Love et al. 2011; Holloway et al. 2012; Bhatt et al. 2016). Thus, since the model approach employed herein explicitly treats convection, it has an inherent advantage. The easterly composite of TRMM exhibits slightly slower westward rainfall propagation within the range of Borneo, with this Borneo rainfall feature also appearing longer lived than that in WRF. Nevertheless, the overriding phase speed of $\sim 17 \mathrm{~m} \mathrm{~s}^{-1}$ is apparent in both TRMM and WRF, with continuity of convection between Borneo, Sumatra, and the eastern Indian Ocean.

The $u^{\prime}$ result from ERA5 indeed has evidence of this diurnal propagating mode, as is especially clear in the easterly regime (Fig. 4c). Namely, upper-level diffluent flow appears in the vicinity of rainfall, especially over Sumatra, and this pattern shifts westward with time $\left(\sim 100^{\circ}-105^{\circ} \mathrm{E}\right)$. This signal is strongly disrupted by model cycling and data assimilation, however, which causes spurious temporal discontinuities (these similarly appear on individual days in a full Hovmöller diagram; not shown). We may also assume that the diurnal cycle in ERA5 is strongly influenced by the use of convective parameterization, which notoriously degrades the representation of the diurnal cycle (Holloway et al. 2012, and references therein). Thus, while reanalysis is inadequate to study this propagating mode, the consistencies between TRMM, ERA5, and WRF provide strong validation of the WRF simulation.

The zonal wavelength of this disturbance implies a very high zonal wavenumber, and a period $\tau \sim 1$ day through $\tau=\lambda_{x} / c_{x}$. Tropical wave modes of such wavenumbers and frequency likely only include gravity waves (Kiladis et al. 2009). Evidence provided later indeed confirms that this upper-tropospheric $u^{\prime}$ signal is the manifestation of a zonally propagating gravity wave mode forced by convection in the MC (Fig. 4a).

Ichikawa and Yasunari (2007) also investigated these diurnally linked, zonally propagating systems in the MC, and similarly noted phase speeds of $15-20 \mathrm{~m} \mathrm{~s}^{-1}$. They argued that this propagation speed is similar to the wind speed around $600 \mathrm{hPa}$; however, in their analysis, wind speed at this level changes drastically across longitude, despite nearly invariant phase speed (their Fig. 6). Furthermore, Figs. 3a and $3 \mathrm{~b}$ demonstrate that wind speed is far slower than phase speed in the two regimes studied here. This implies the importance of 
intrinsic propagation. This phase speed is indeed similar to that of offshore-propagating diurnal gravity waves investigated in the Panama Bight region (Mapes et al. 2003a,b; Warner et al. 2003), the Bay of Bengal (Yang and Slingo 2001; Zuidema 2003), and the South China Sea (Aves and Johnson 2008).

Both in WRF and TRMM the more continuous system of the easterly regime is characterized by dramatically increasing rainfall magnitude from $\sim 1300$ to 1600 LST over Borneo (Figs. 4a,c). This local convective initiation appears to take place near both the eastern and western Borneo coastlines, although peak rainfall is near $115^{\circ} \mathrm{E}$, that is, Borneo's highest terrain (Fig. 1). This Borneo rainfall system peaks from $\sim 1900$ to 0100 LST and persists through midnight as it shifts westward, weakening around 0400 LST in WRF and 0700 LST in TRMM. Rainfall then increases again near the western Borneo coastline around 0700 LST in WRF and 1000 LST in TRMM. Following this secondary initiation, rainfall moves westward out to sea and persists into the subsequent early afternoon. Both WRF and TRMM suggest that this rainfall feature, although weaker around midday, has spatiotemporal continuity with the diurnal rainfall over and west of Sumatra, which intensifies beginning at $\sim 1900$ LST. This now-Sumatra rainfall feature maintains its strength overnight, and dramatically weakens the subsequent morning by $\sim 1000$ LST. Yet the upperlevel $u^{\prime}$ signal appears to continue out to at least $80^{\circ} \mathrm{E}$.

Similar to the easterly diurnal composite, rainfall in the westerly composite also initiates in the midafternoon within the longitudes of Borneo, and in the coastal regions in particular (Figs. 4b,d). Rainfall then peaks between 1900 and 0100 LST over central Borneo, similar to that in the easterly regime. This rainfall system is nevertheless highly discontinuous overnight as it shifts offshore. The cause for this distinction is unknown. This diurnal evolution is generally consistent with that described in two analogous flow regimes by Ichikawa and Yasunari (2006).

The remainder of the analysis is dedicated to exploring the easterly regime in greater detail, given its much greater spatiotemporal continuity (Figs. 2 and 4). We do not further analyze the westerly regime; however, we discuss how the findings concerning the easterly regime likely extend to the westerly regime in section 4 .

Maps of rainfall and 10-m divergence for the easterly regime reveal the pronounced evolution of both diurnal land-sea breezes and mountain-valley solenoidal circulations, which are responsible for diurnal convective initiation (Fig. 5). Rainfall is spatially smoothed in Fig. 5 to emphasize its footprint at the mesoscale. The corresponding maps of TRMM rainfall for the easterly regime reveal remarkable overall consistency with WRF (online supplemental material). The daytime strengthening of sea breezes is evident along each coastline by 1300 LST as bands of enhanced divergence just offshore, areas of convergence inland along the coasts, and inland-directed flow at the coasts. Centers of convergence inland, for example, in Borneo, are the result of mountain-valley solenoidal circulations (Ichikawa and Yasunari 2006; Bao and Zhang 2013). At 1300 LST most islands are characterized by relatively small-scale, scattered rainfall centers both along coastlines and inland, indicating early stages of convective storm development.

A pronounced upscale growth of convection takes place through the evening (Fig. 5). By 1600 LST rainfall has substantially increased along focused areas of sea-breeze-induced convergence, such as along western coastal Sumatra and western Borneo. At this time rainfall is also evident along the steeply sloped terrain of northern Sumatra, northeastern Borneo, and in the lower Malay Peninsula. By 1900 LST the aforementioned rainfall centers have mostly intensified and further clustered, indicative of upscale growth (Houze et al. 1981; Johnson and Priegnitz 1981). The rainfall maximum in northeastern Borneo has shifted southwestward, following both the coastline and sloped terrain (Fig. 1). By 2200 LST westward movement is now evident in three pronounced rainfall centers: one moving offshore from Sumatra, one moving offshore from the western Malay Peninsula, and one in centralnorthern Borneo. This westward movement continues from 2200 through 0400 LST. Each of the rainfall centers have substantially weakened by 0700 LST, although continued westward movement of the Borneo and Sumatra rainfall centers is apparent. The rainfall center originating in the Malay Peninsula has become anchored to the upwind (eastern) coastline of Sumatra.

Land breezes have become prominent by 0400 LST, and by 0700 LST new localized rainfall centers appear along the coasts around Borneo because of land-breeze convergence. The Borneo rainfall system of the overnight period has largely died inland, yet along the coast it has become coupled with the land breeze, which likely sustains it while it continues westward movement as a smaller and weaker system (Houze et al. 1981). From 0700 to 1300 LST each of the above-described rainfall maxima suffer nearly complete loss of identity as they continue westward, thereafter being dominated by the next diurnal cycle.

The life cycle of the easterly composite system is further depicted through zonal cross sections of vertical velocity $w$ across the MC and eastern Indian Ocean (Fig. 6a). Over Borneo, a strong maximum of rising 


\section{Rainfall and Divergence}
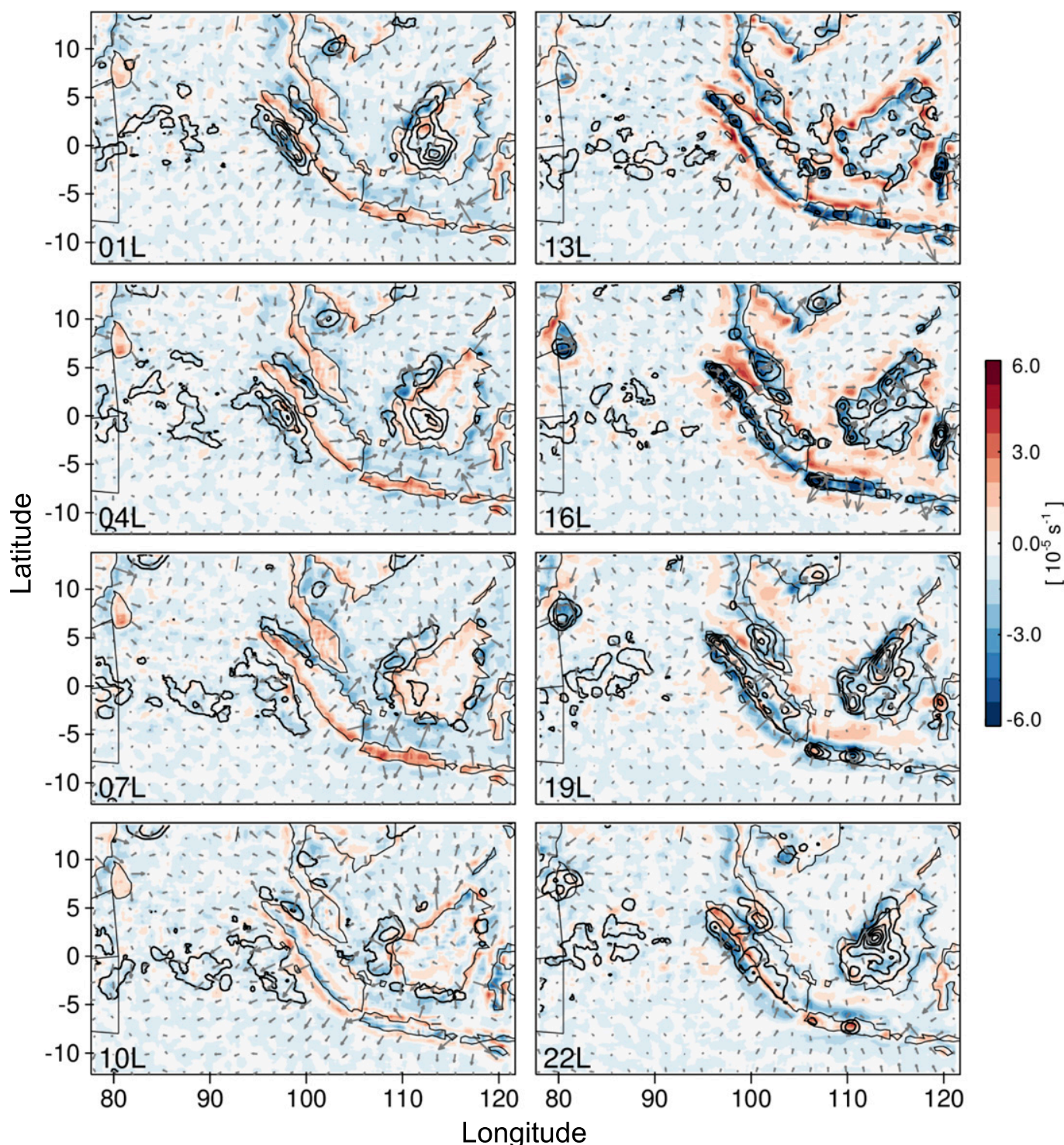

FIG. 5. Maps for the easterly composite of rainfall (contoured every $15 \mathrm{~mm}^{-1} \mathrm{y}^{-1}$ ), $10-\mathrm{m}$ divergence with the time mean subtracted (shaded), and 10-m wind (vectors; largest vector is $3 \mathrm{~m} \mathrm{~s}^{-1}$ ) with the time mean subtracted. All fields are from WRF (here and henceforth). Variables are smoothed using $1^{\circ}$ binning.

motion appears from 1600 to 1900 LST, which is associated with the dramatic increase in rainfall in northerncoastal Borneo in that same 3-h period (Fig. 5). A weaker maximum appears in association with the western coastal rainfall maximum. From 1900 to 0400 LST the stronger convective system shifts westward at a rate of $\sim 8 \mathrm{~m} \mathrm{~s}^{-1}$, and then weakens. As it weakens, the aforementioned coastal rainfall system linked to the land breeze becomes the dominant system, which propagates offshore (westward) at a similar phase speed. Recent modeling studies suggest that daytime shortwave radiative absorption by anvil clouds invigorates upper-level rising motion (Ruppert and Hohenegger 2018; Ruppert and Klocke 2019). This mechanism may help explain why this offshore system endures through noon on the second day, though further modeling sensitivity studies are needed to test this notion.

The remnants of this offshore-propagating system move into the region of the lower Malay Peninsula and eastern Sumatra by 1600-1900 LST on the next day, as new rainfall elements develop and grow upscale in both island regions (Fig. 6a). A vigorous mesoscale 


\section{Zonal Transect: Vertical Motion}

(a)

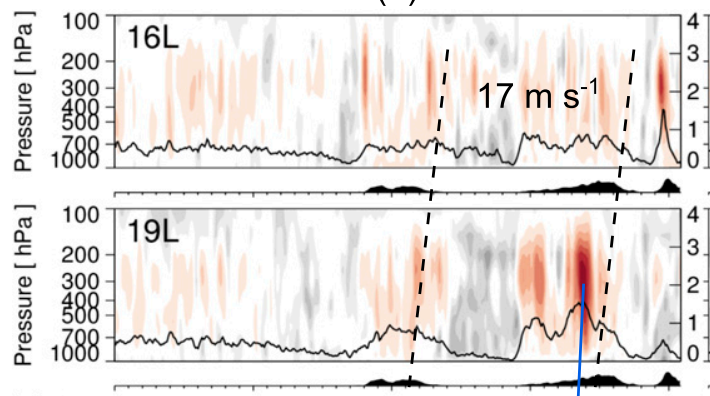

(b)
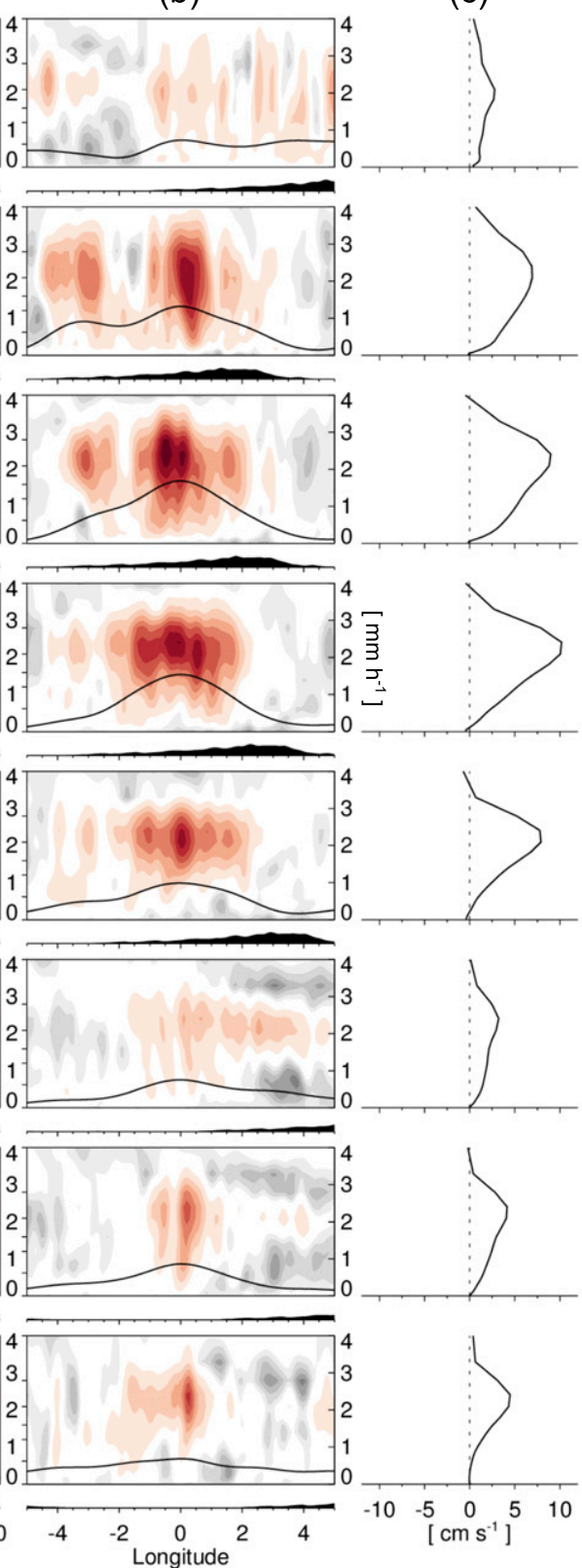

FIG. 6. (a) Easterly composite zonal cross sections of $w$ averaged from $3^{\circ} \mathrm{S}$ to $3^{\circ} \mathrm{N}$ as a function of LST. Topography is shown (not according to scale) beneath each panel. Rainfall is plotted according to the right ordinate. Westward phase speeds of 17 (black dashed line) and $8 \mathrm{~m} \mathrm{~s}^{-1}$ (blue solid line) are indicated. (b) A Lagrangian, zoomed-in depiction of the Borneo convective system, with the smoothed rainfall trace employed for the tracking (see text for details). (c) Mean profiles of $w$ zonally averaged over $2.5^{\circ}$ about the rainfall peak in (b). Red brackets along abscissa of (a) provide longitudinal averaging bands for Fig. 8.

convective system appears along coastal Sumatra by 2200-0100 LST, after which time its evolution closely synchronizes with that in Borneo (Figs. 5 and 6a).

The analysis thus far suggests that the phase speed $c_{x} \sim-17 \mathrm{~m} \mathrm{~s}^{-1}$ apparent in the Hovmöller view of rainfall
(Figs. 4a,c) is caused by the orchestration of sequential convective life cycles along a westward trajectory. The individual convective elements often propagate westward at a substantially slower phase speed, however. This suggests that an overriding entity-such as a 
gravity wave-helps to orchestrate these sequential convective systems.

A Lagrangian view of the Borneo convective system is devised by tracking its local rainfall maximum (Fig. 6b). To do so, rainfall is first smoothed using a Gaussian filter with a seven-point standard deviation, as shown in Fig. 6b. This tracking therefore inherently takes on westward motion of $\sim 8 \mathrm{~m} \mathrm{~s}^{-1}$. This Lagrangian view emphasizes the dramatic upscale growth of the system: from scattered, much weaker convection at 1600 LST, to an extensive, intense mesoscale convective complex by 0100 LST as it shifts westward downslope. The width of this zone of upward motion is $\sim 500 \mathrm{~km}$. Mean profiles of vertical motion are generated by averaging across this rainfall maximum (Fig. 6c). Since vertical motion dominates the apparent heat source to first order, these profiles shed light on the nature of these convective systems (Yanai et al. 1973; Johnson 1982; Haertel and Kiladis 2004). The system always features a peak in upward motion near $300 \mathrm{hPa}$, indicative of a large proportion of stratiform precipitation and evaporatively cooled downdrafts (Zipser 1977; Mapes and Houze 1995; Houze 1997). Maximum upward motion is $10 \mathrm{~cm} \mathrm{~s}^{-1}$ (at 0100 LST), very similar to observational estimates of mesoscale-averaged upward motion documented by Johnson (1982).

This predominately nocturnal mesoscale convective system has been well documented in an easterly flow regime through the International Winter Monsoon Experiment (WMONEX) of December 1978. The resulting observations demonstrated a late-night development (or redevelopment) of convection along the western coastal region of Borneo in connection with the land breeze, resulting in dramatic upscale growth. Moreover, the observations demonstrated a contiguous mesoscale convective system with an extensive, dominant stratiform rain region (of similar scale to that in Figs. $6 \mathrm{a}$ and $6 \mathrm{~b}$ ) and top-heavy vertical motion signature (Houze et al. 1981; Johnson and Priegnitz 1981; Johnson 1982; Johnson and Kriete 1982). The model results described herein are therefore highly consistent with observational findings.

Given the general consistency of the model results with previous observational findings, we move forward to investigate the fundamental nature of the continuous rainfall disturbance in the easterly composite regime (Fig. 4a). Zonal cross sections of $u^{\prime}$ and $\theta_{v}^{*}$ are shown in Fig. $7\left(\theta_{v}^{*}\right.$ is virtual potential temperature $\theta_{v}$ filtered for variability on zonal scales smaller than $20^{\circ}$ in longitude). The $u^{\prime}$ exhibits greatest amplitude in the upper troposphere in association with divergence above the strongest deep convection (Figs. 7a and 6). The amplitude of this upper-level $u^{\prime}$ signal evolves throughout the diurnal cycle in accordance with the diurnal evolution of mesoscale convective systems (Figs. 4a, 5, and 6). Yet this upper-tropospheric signal clearly maintains substantial continuity as it transits westward at $\sim 17 \mathrm{~m} \mathrm{~s}^{-1}$ from Borneo to Sumatra, then out to sea.

The ever-present westward-tilted rays in $\theta_{v}^{*}$ in the upper troposphere, roughly in quadrature with anomalies in $u^{\prime}$, are consistent with the generation and upward propagation of a gravity wave energy forced by a westward-moving heat source (Figs. 7a,b) [see discussions of forced gravity waves by Kiladis et al. (2009) and Wheeler and Nguyen (2015)]. This westward tilt was also demonstrated in the specific case of 2-day inertia-gravity waves by Takayabu et al. (1996). These patterns are characterized by a vertical wavelength of $\lambda_{z} \sim 7 \mathrm{~km}$, and zonal wavelength $\lambda_{x} \sim 1500 \mathrm{~km}$ (matching that in $u^{\prime}$ and rainfall; Fig. 4). Although these patterns change from one time to the next in response to changes in convective activity, westward movement is evident, approximately matching the phase speed of $\sim 17 \mathrm{~m} \mathrm{~s}^{-1}$ in rainfall (Fig. 4).

The diurnal variation of these patterns is depicted in Fig. 8 through time-height series averaged over the strong convective systems of Borneo and Sumatra, and that in between over the Karimata Strait. These three composites are generated by averaging spatially from $3^{\circ} \mathrm{S}$ to $3^{\circ} \mathrm{N}$ and the three longitude bands indicated in Fig. 6a, and as a function of local time for all days of the easterly composite. The vertical alignment of anomaly patterns in $\theta_{v}^{*}, u^{\prime}$, and $w$ is consistent with a westward-moving convectively generated heat source, as described in relation to convectively coupled 2-day waves by Haertel and Kiladis (2004). For example, over Borneo around the time of strongest rainfall $(\sim 1900$ 0100 LST; Figs. 6 and 8$)$, a warm $\theta_{v}^{*}$ anomaly is centered from $\sim 200$ to $300 \mathrm{hPa}$, with cold anomalies above and below; divergence maximizes above this warm anomaly, with convergence from 500 to $300 \mathrm{hPa}$, and divergence near the surface. The vertical signatures in $u^{\prime}$ and $\theta_{v}^{*}$ are therefore in approximate quadrature, in agreement with the theoretical signal for a vertically propagating forced gravity wave, as noted above. These vertical patterns can be described to first order as the linear sum of the first and second internal modes, which relate to convective and stratiform heating, respectively (Mapes 1993; Haertel and Kiladis 2004). Similar vertical patterns appear in relation to peaks in rainfall over both Sumatra and the Karimata Strait, while patterns of opposite sign appear at each location when rainfall is suppressed.

These patterns suggest a gravity wave mode that is coupled to and excited by the synchronized, vigorous nocturnal convective systems over Sumatra and Borneo 


\section{Zonal Transects}

(a) $u^{\prime}$
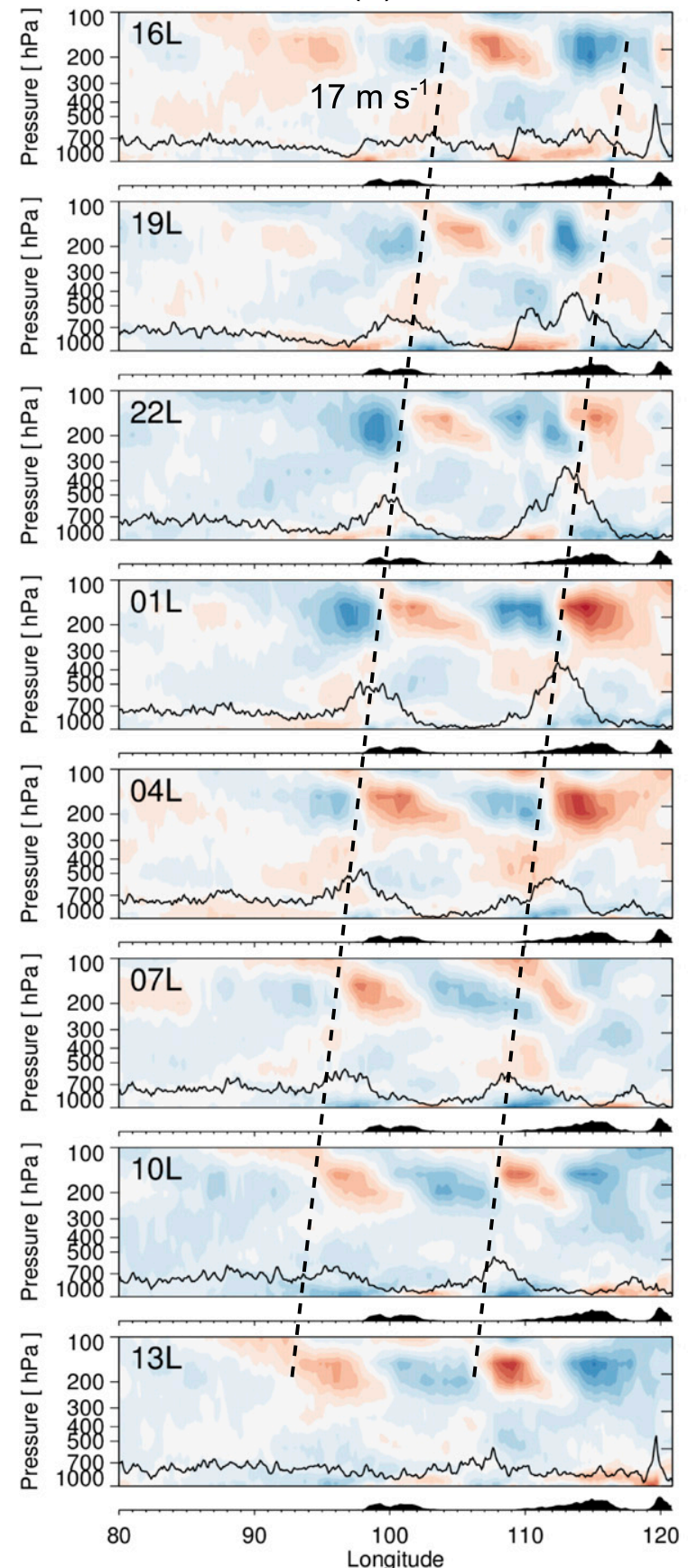

(b) $\theta_{v}^{*}$

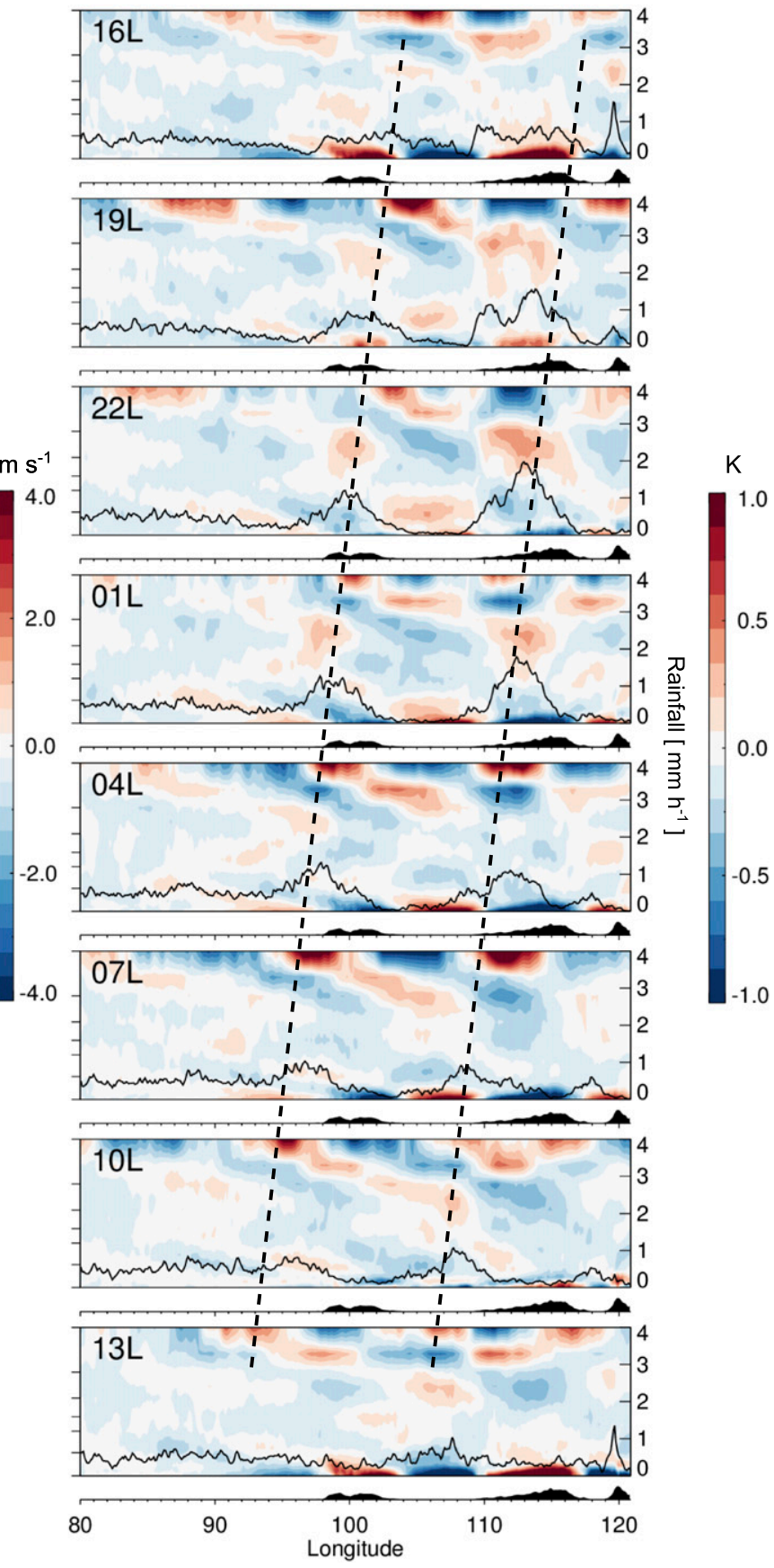

FIG. 7. As in Fig. 6a, but for (a) $u^{\prime}$ and (b) $\theta_{v}^{*}$, which is virtual potential temperature $\theta_{v}$ filtered by subtracting the time mean and the $20^{\circ}$ running zonal average.

(Figs. 6 and 8). This gravity mode hence assumes a zonal wavelength of $\sim 1500 \mathrm{~km}$, roughly matching the spacing between these two systems. Despite the slower phase speed of individual convective systems, signals in both upper-level divergence and $\theta_{v}^{*}$ suggest the quasi-continuous westward propagation at a phase speed $c_{x} \sim 17 \mathrm{~m} \mathrm{~s}^{-1}$, as in Fig. 4a.

A horizontal view of gravity wave activity is provided through spatial maps of $\theta_{v}^{*}$ at $700 \mathrm{hPa}$ (Fig. 9). A signal closely resembling a gravity wave mode in the equatorial 


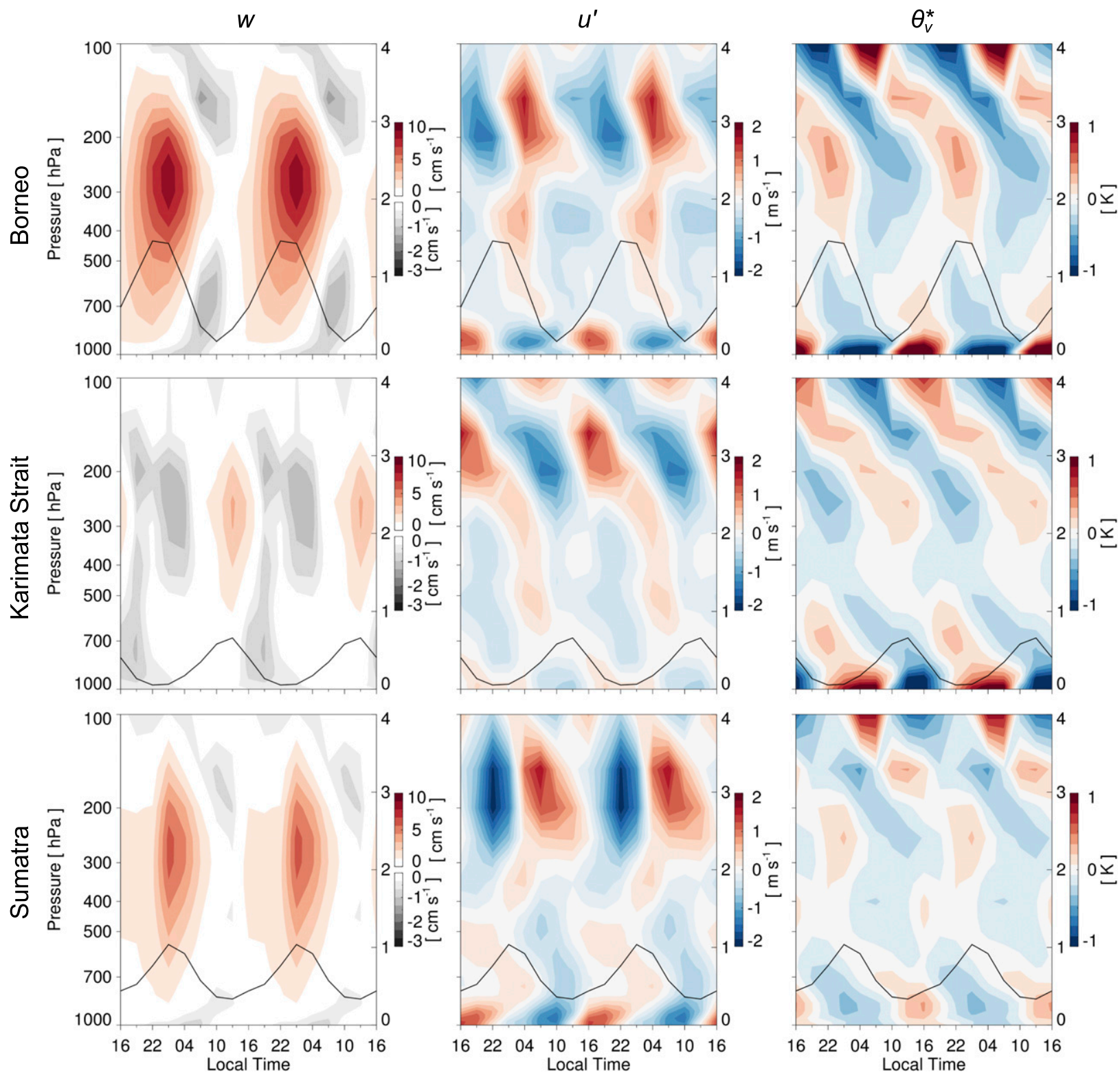

FIG. 8. Easterly composite time-height sections of (left) $w$, (center) $u^{\prime}$, and (right) $\theta_{v}^{*}$ averaged from $3^{\circ} \mathrm{S}$ to $3^{\circ} \mathrm{N}$ and across the longitudinal bands shown along the abscissa of Fig. 6, which are for the rainfall systems of (top) Borneo, (middle) Karimata Strait, and (bottom) Sumatra. Rainfall is plotted according to the right ordinate $\left(\mathrm{mm} \mathrm{h}^{-1}\right)$.

region extends as far west as $\sim 70^{\circ}-80^{\circ} \mathrm{E}$, similar to the signal in $u^{\prime}$ at $150 \mathrm{hPa}$ (Fig. 4a). More generally, the patterns in $\theta_{v}^{*}$ emphasize the influence of unique geography on gravity wave activity across the MC. For example, at 1900 LST diagonally oriented warm anomalies appear to effectively enwrap Borneo both to the north and to the south, likely because of forced subsidence between the strong deep convection over land (Fig. 6). Similarly, the signal in the vicinity of Sumatra takes on the characteristic northwest-southeast orientation of this island, and is likely related to the offshore-propagating gravity waves discussed in the modeling study by Love et al. (2011).

The $\theta_{v}^{*}$ signal at $700 \mathrm{hPa}$ exhibits enhanced localized peaks in the equatorial MC at 2200 LST, with cold anomalies over Sumatra and Borneo and a warm anomaly of similar magnitude between them (Fig. 9). This is $\sim 3 \mathrm{~h}$ following the dramatic upscale growth and intensification of deep convection over Borneo, consistent with the above notion that gravity wave-convection coupling is favored at these particular times of the diurnal cycle when this convective evolution takes place 
Rainfall and $\theta_{v}^{*}$ at $700 \mathrm{hPa}$
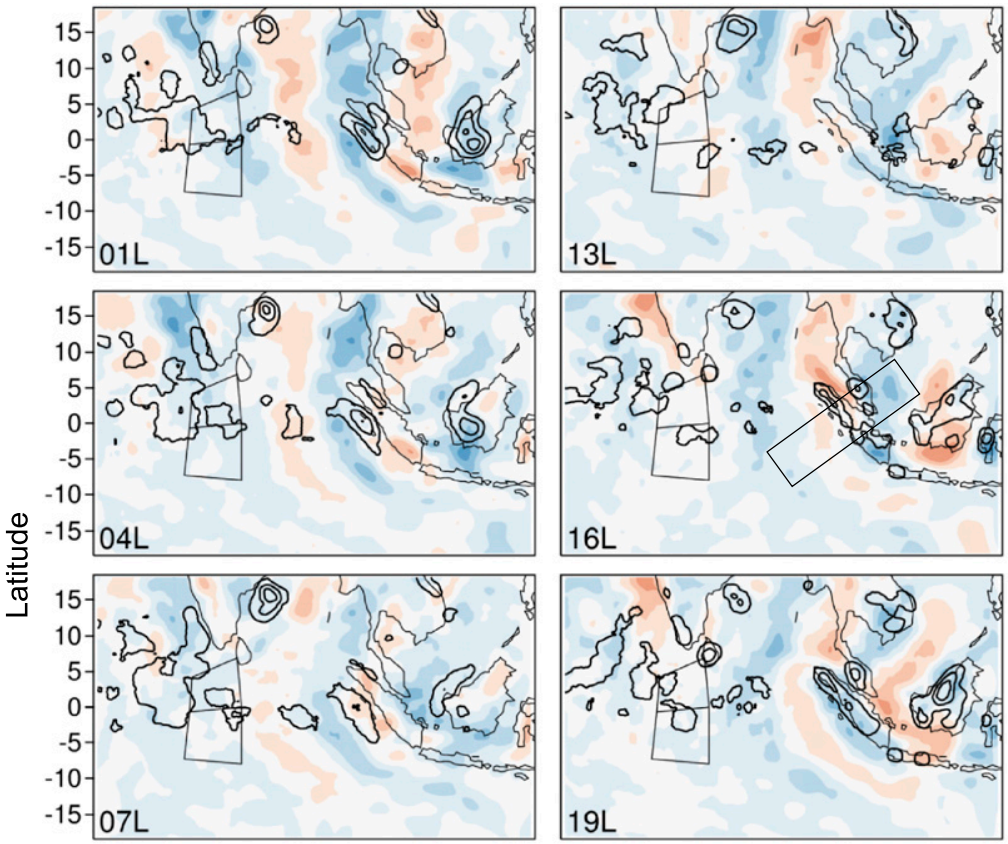

$13 \mathrm{~L}$
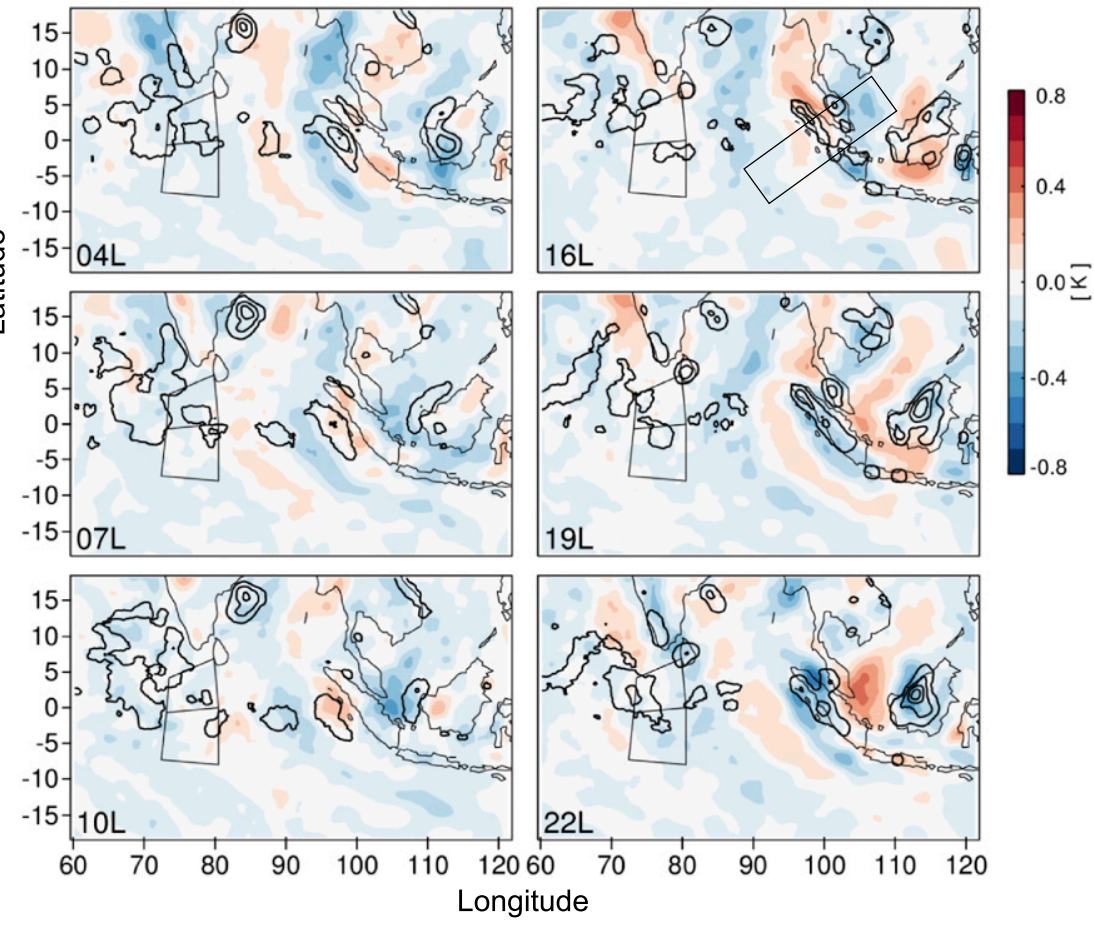

FIG. 9. As in Fig. 5, but with $\theta_{v}^{*}$ at $700 \mathrm{hPa}$ (shaded). Variables are smoothed using $2^{\circ}$ binning. The Sumatra transect of Figs. 10 and 12 is shown in the panel for 1600 LST.

(Fig. 6). Although the amplitude of this $\theta_{v}^{*}$ signal varies dramatically in accordance with the vigor of deep convection, it maintains a substantial measure of continuity as it propagates westward (or southwestward).

To assess the character of the northwest-southeastorientated gravity wave mode tied to Sumatra (Fig. 9), Fig. 10 provides cross sections of $u^{\prime}$ and $\theta_{v}^{*}$ generated from the cross-Sumatra transect shown in Fig. 9, with fields averaged across the narrow dimension. There is evidence of fast propagation in the northeastern portion of the cross section, at a rate $c_{\theta}=c_{x} \cos \theta \sim-1 \mathrm{~s}^{-1}$, where $\theta$ is the angle $\left(36^{\circ}\right)$ of the transect from zonal; that is, this propagation likely corresponds with the zonally propagating mode described above. Yet in the offshore region from Sumatra, the divergent flow exhibits southwestward propagation of $\sim-7 \mathrm{~m} \mathrm{~s}^{-1}$ linked with the propagation of the nocturnal mesoscale convective system (similar to Fig. 6). This phase speed is similar to that noted by Love et al. (2011).
Nevertheless, southwestward-tilted rays in $\theta_{v}^{*}$ and $u^{\prime}$ are also apparent, indicative of upward radiation of gravity wave energy in connection with this convective system (Fig. 10b).

The above suggests that the fast gravity wave mode identified in Fig. 4a, which propagates zonally at a rate of $\sim 17 \mathrm{~m} \mathrm{~s}^{-1}$, is distinct from the mode propagating southwestward away from Sumatra at a slower rate of $\sim 7 \mathrm{~m} \mathrm{~s}^{-1}$ (Fig. 9). The cause for this distinction in phase speed remains unclear; however, density current theory may at least shed light on the propagation rate of individual rainfall systems. This is explored next.

Cross sections depicting the low-level atmospheric structure, both in the zonal and in the diagonal (crossSumatra) contexts, are provided in Figs. 11 and 12. In the boundary layer over and west of Borneo, low-level isentropes (of constant $\theta_{v}$ ) reveal a localized surfacebased cold anomaly extending from the landmass across the coastline from $\sim 2200$ to 0700 LST (Fig. 11). 
(a) $u_{d}^{\prime}$

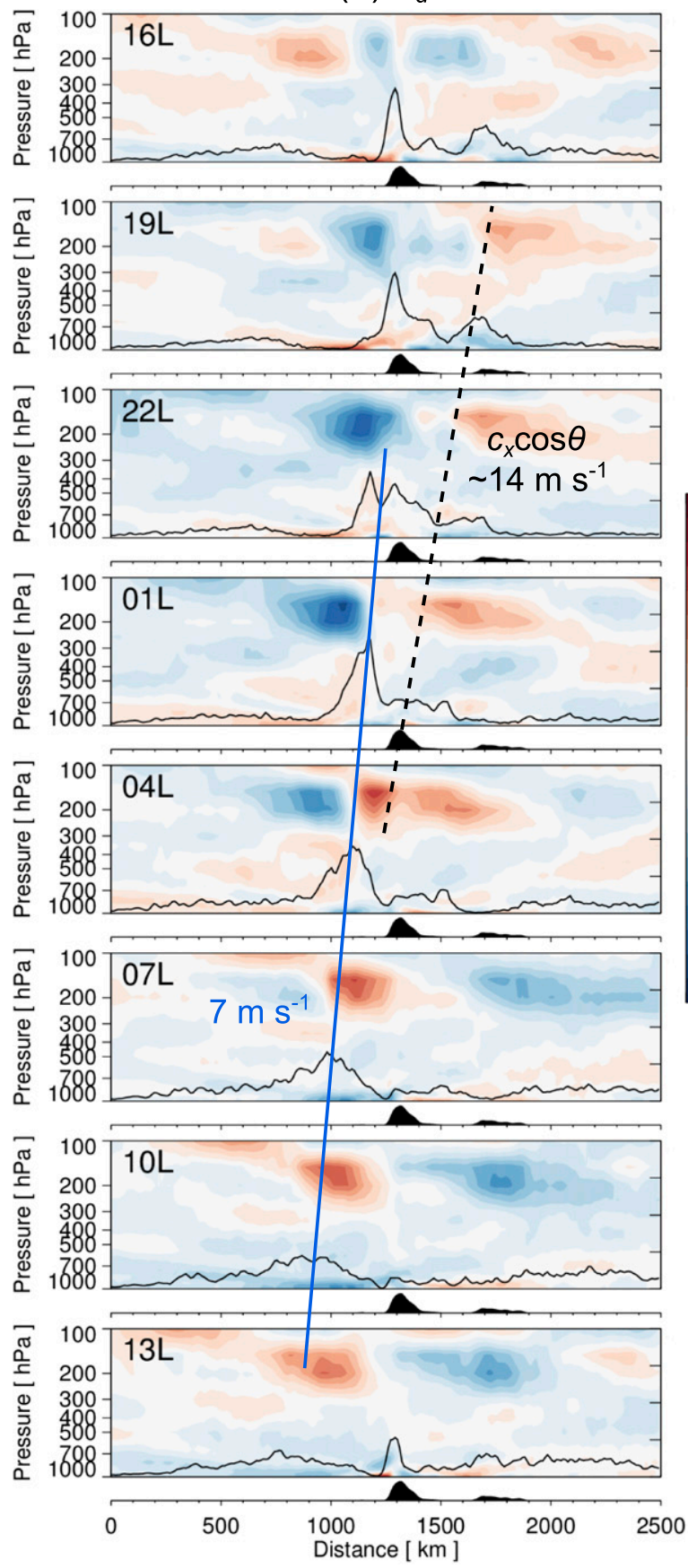

(b) $\theta_{v}^{*}$
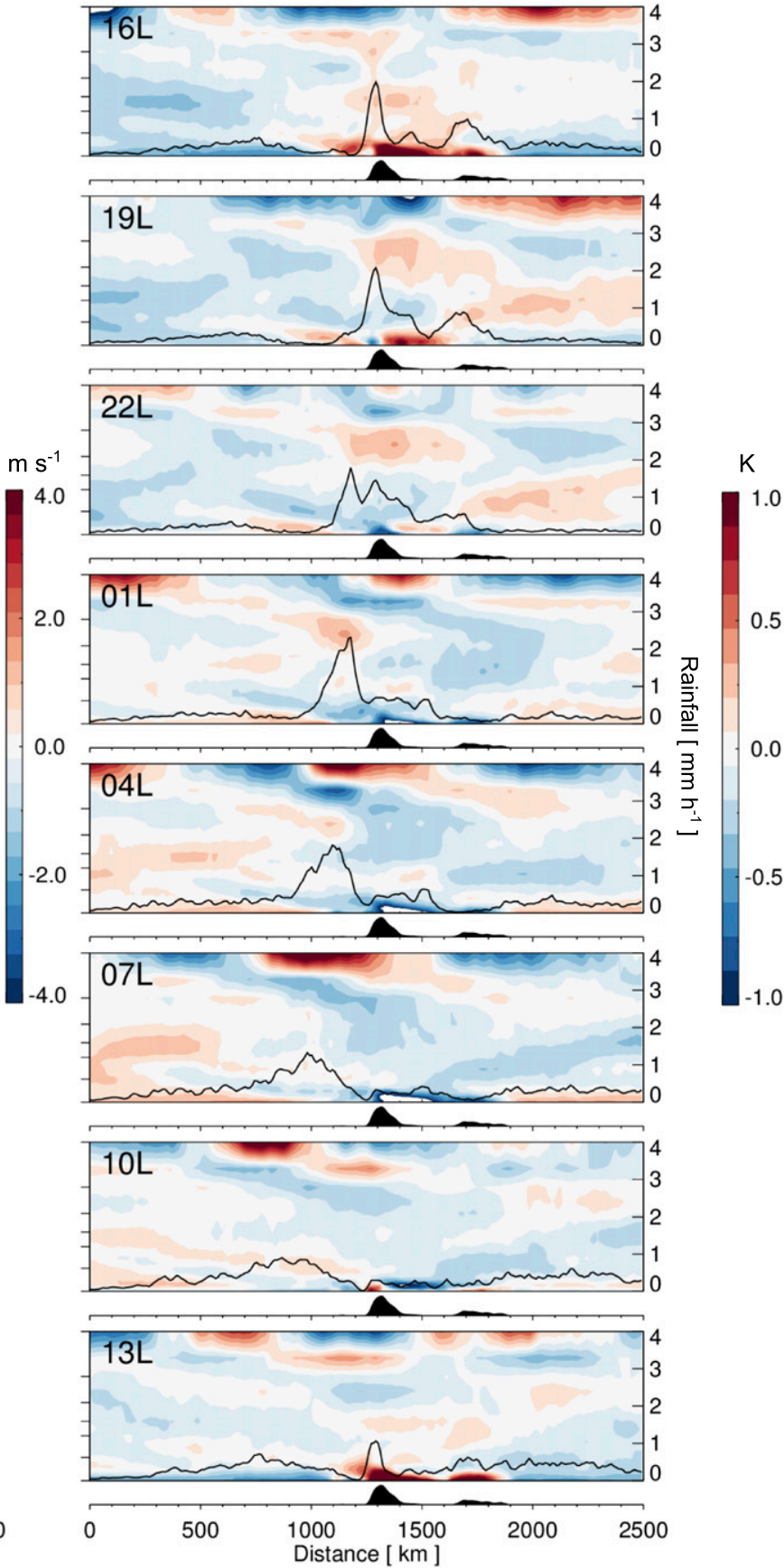

FIG. 10. As in Fig. 7, but along the diagonal transect across Sumatra shown in Fig. 9 (averaged across the narrow dimension; oriented from southwest to northeast from left to right). Southwestward phase speeds of 14 (black dashed line) and $7 \mathrm{~m} \mathrm{~s}^{-1}$ (blue solid line) are indicated.

This cold anomaly is partly caused by convectively generated downdrafts (i.e., cold pools) and partly by nocturnal land surface cooling (land breeze and katabatic flows; Houze et al. 1981; Johnson and Kriete 1982). From 0400 to 1000 LST, easterly-flow anomalies of magnitude $\sim 2 \mathrm{~ms}^{-1}$ appear in the boundary layer near the leading (western) edge of this cold anomaly, which extend downward from aloft. This wind signature is consistent with downward convective momentum transport. The development of downdrafts is consistent with 


\section{Zonal Transects}

(a) $u^{\prime}$
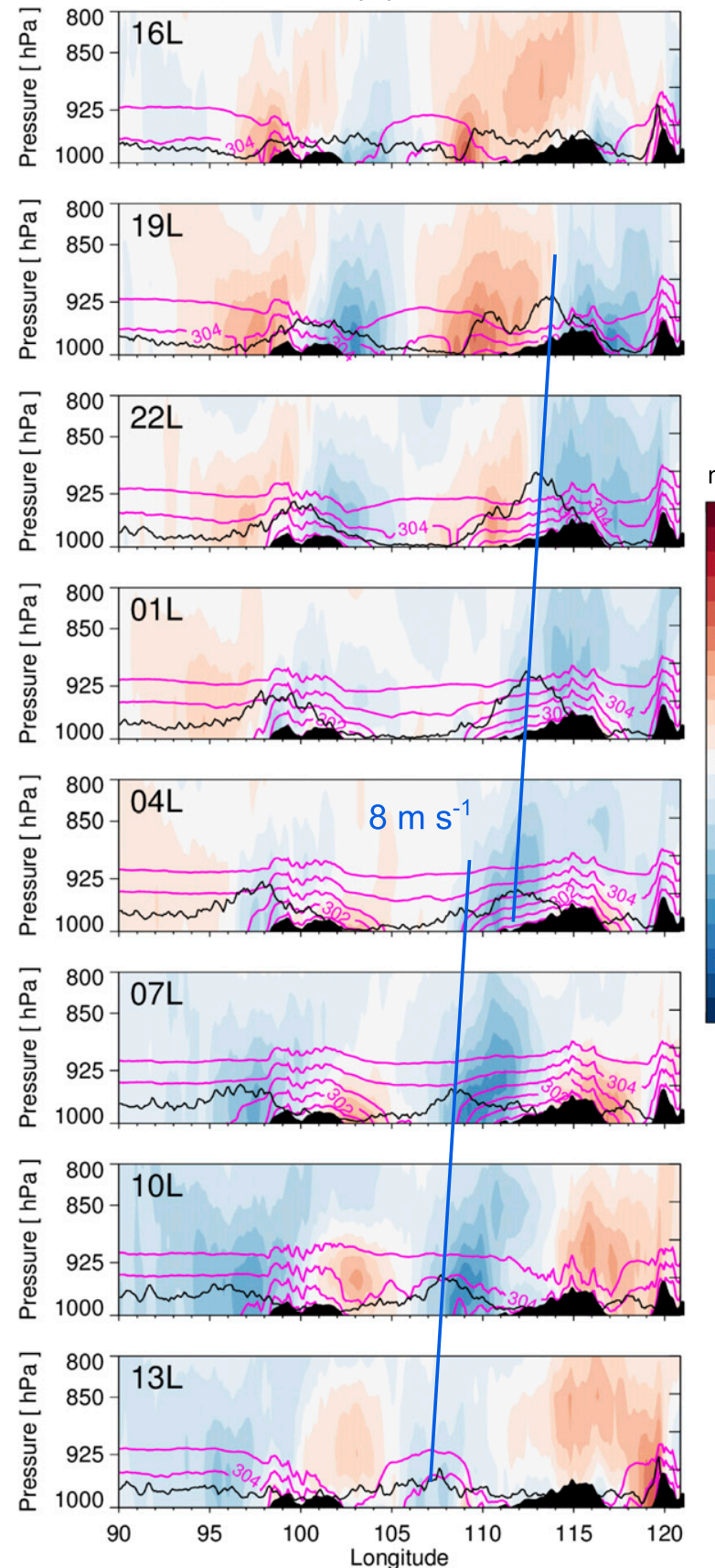

(b) $\theta_{v}^{*}$
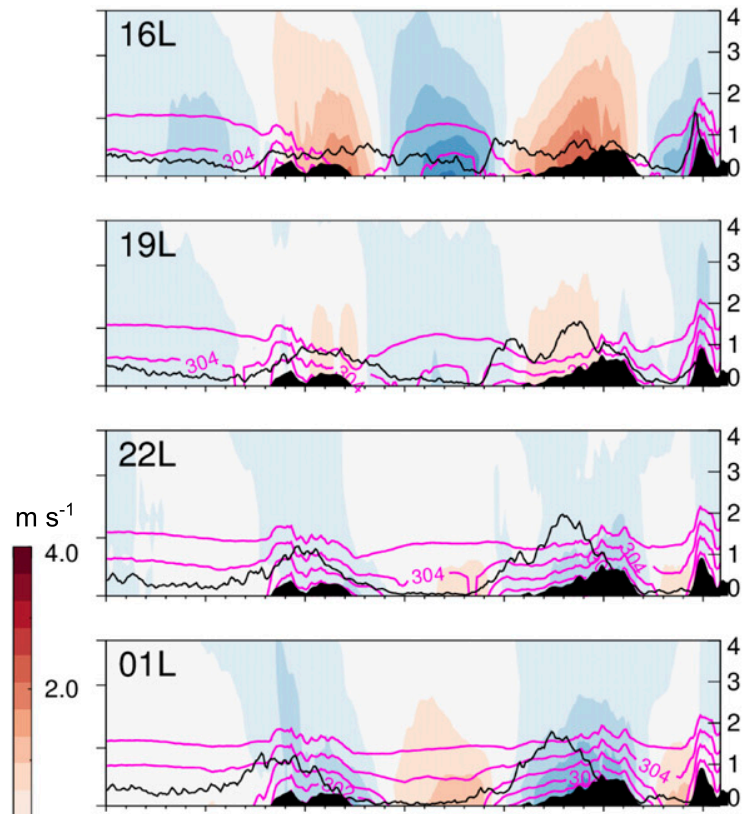

0.0

$-2.0$

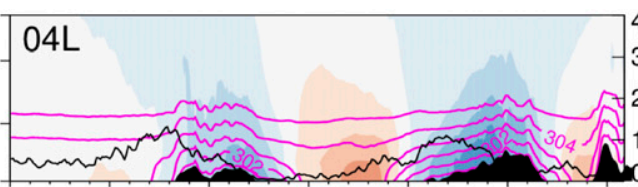

07L

.0
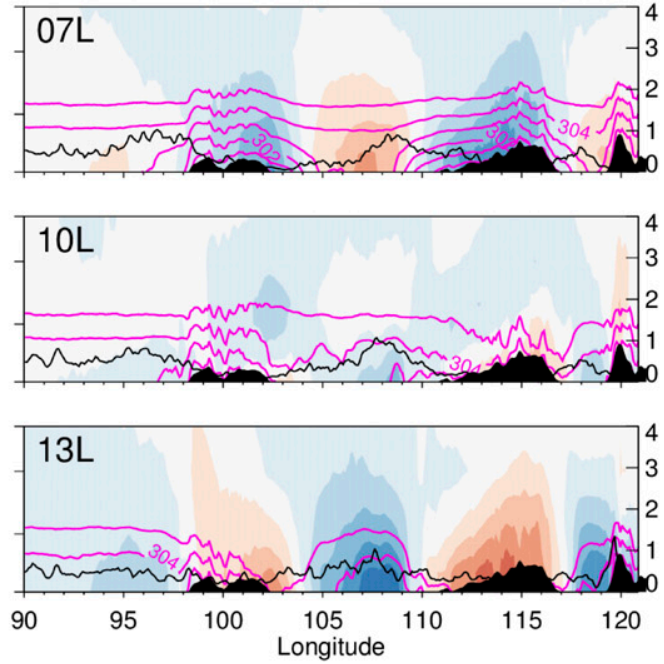

FIG. 11. (a) As in Fig. 7, but with terrain overlaid (to scale) and contours of $\theta_{v}$ every $1 \mathrm{~K}$ from 300 to $305 \mathrm{~K}$. Westward phase speed of $8 \mathrm{~m} \mathrm{~s}^{-1}$ is indicated (blue lines).

the very top-heavy nature of these organized convective systems, which implies the prevalence of stratiform rainfall processes (Fig. 6; Houze et al. 1981; Zipser 1977).

Density current phase speed can be estimated from theory as $C \approx \sqrt{b^{\prime} H}$, where $b^{\prime}=g \Delta \theta_{v} / \bar{\theta}_{v}$ is the buoyancy anomaly, $g$ is gravity, $\Delta \theta_{v}$ is the $\theta_{v}$ difference across the density current front, and $H$ is its height (Markowski and Richardson 2010). We assume $H \sim 500 \mathrm{~m}$, which is the approximate height of vertically sloped isentropes in Fig. 11. Then taking $\Delta \theta_{v} \sim 3 \mathrm{~K}$ and $\bar{\theta}_{v} \sim 300 \mathrm{~K}$ (Fig. 11) yields a phase speed $C \sim 7 \mathrm{~m} \mathrm{~s}^{-1}$. This estimate is highly consistent with the evident phase speed of individual 
(a) $u^{\prime}$
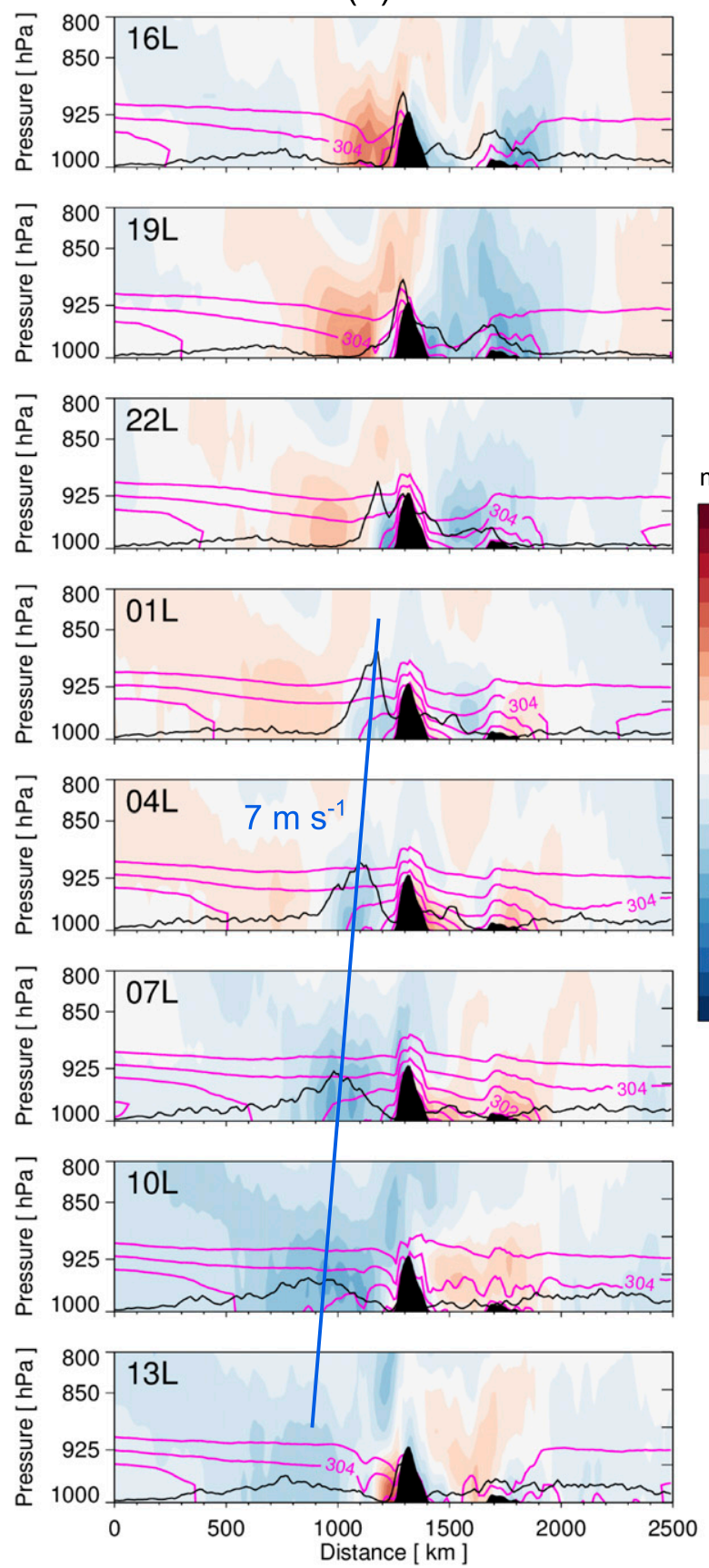

FIG. 12. As in Fig. 11, but along the diagonal transect across Sumatra shown in Fig. 9 (averaged across the narrow dimension; oriented from southwest to northeast from left toright). Southwestward phase speed of $7 \mathrm{~m} \mathrm{~s}^{-1}$ is indicated (blue line).

rainfall elements, implying that the propagation of these systems may be explained by density current dynamics (Figs. 6, 7, and 10). Isentropes in the Sumatra transect suggest a slightly weaker cold anomaly of $\Delta \theta_{v} \sim 1-2 \mathrm{~K}$, which yields $C \sim 4-6 \mathrm{~m} \mathrm{~s}^{-1}$ (Fig. 12). This is nevertheless in approximate agreement with the (b) $\theta_{v}^{*}$
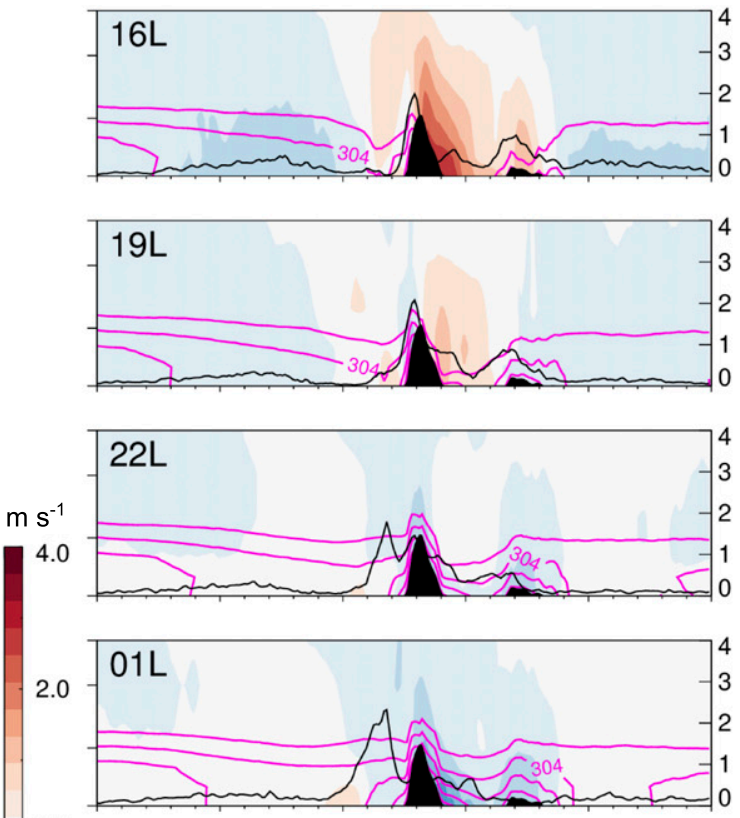

2.0
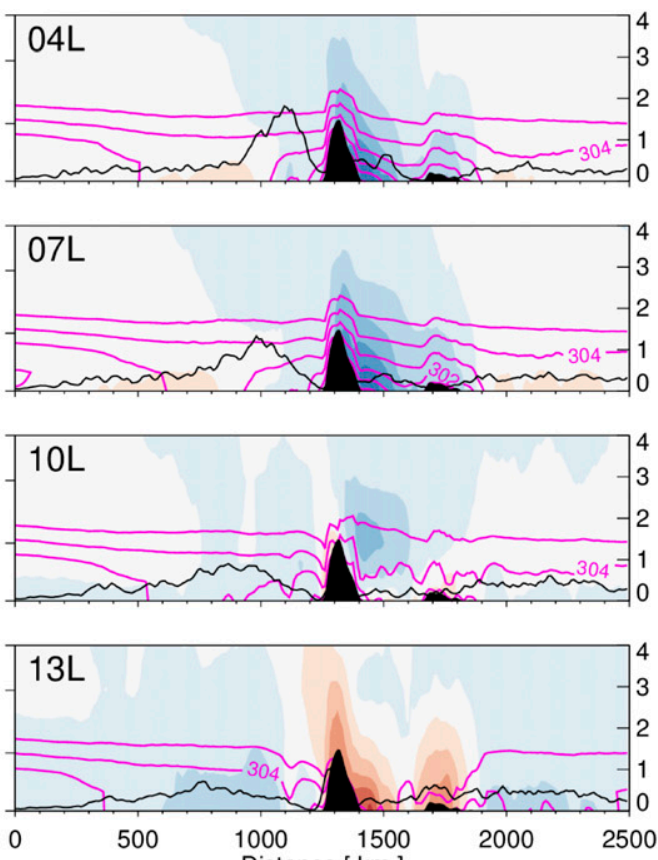

apparent southwestward propagation rate of rainfall elements therein.

This analysis suggests two distinct gravity wave modes in the easterly regime: 1) a fast mode that propagates westward at a rate of $\sim 17 \mathrm{~m} \mathrm{~s}^{-1}$ and 2) a slower mode that propagates southwestward at $\sim 7 \mathrm{~m} \mathrm{~s}^{-1}$ away from 
Sumatra. Both modes are associated with clear evidence of upward radiation of gravity wave energy forced by a propagating heat source. An intriguing finding is that, in both cases, mesoscale convective systems propagate at a rate of 6-7 $\mathrm{m} \mathrm{s}^{-1}$. In consequence, convection along the equatorial region appears to discretely propagate to remain in phase with the faster zonal mode, while there is no clear distinction between the similar motions of the gravity wave and convective system in the case of the southwestward-propagating mode offshore from Sumatra. While the cause for this distinction remains unclear, the motion of individual convective systems $\left(6-7 \mathrm{~m} \mathrm{~s}^{-1}\right)$ is found to be consistent with density current theory.

\section{Discussion}

The spatiotemporal continuity among diurnal rainfall events across multiple islands and diurnal convective life cycles in the MC suggests an overriding propagating disturbance, which orchestrates sequential life cycles along its path at a zonal phase speed of $c_{x} \sim \pm 17 \mathrm{~m} \mathrm{~s}^{-1}$ (Figs. 2 and 4). While these modes are convectively coupled across the MC over $\sim 25^{\circ}$ of longitude $(3000 \mathrm{~km})$, upper-level zonal flow anomalies suggest that the disturbance endures over at least $55^{\circ}(>6000 \mathrm{~km})$ out to sea (Figs. $\left.4 \mathrm{a}, \mathrm{c}\right)$. What is this overriding disturbance?

Our investigation of an easterly-flow regime provides evidence of a westward-propagating gravity wave mode of zonal wavelength $\lambda_{x} \sim 1500 \mathrm{~km}$ (Figs. 6-8). Evidence suggests that the two predominant diurnal mesoscale convective systems-that in Sumatra and that in Borneo-are critical to forcing this gravity wave mode. At the time of day when these systems are strongest $(\sim 1900-0400$ LST) and organized on the largest zonal scales $(\sim 500 \mathrm{~km})$, internal-mode signatures appear in $u^{\prime}, \theta_{v}^{*}$, and $w$ of substantial amplitude that are consistent with those of convectively forced gravity waves described previously (Figs. 6-8) (Kiladis et al. 2009). The mesoscale convective systems individually live and die within a single diurnal cycle, and propagate much slower than $c_{x}$; yet convection appears to reinitiate remarkably in phase with this gravity wave mode, hence suggesting that gravity wave propagation establishes spatiotemporal continuity by initiating sequential rainfall systems along its path (Figs. 4-6). A similar process has been shown to explain the discrete eastward propagation of diurnal convective systems downstream of both the Tibetan Plateau and Rocky Mountains (Pritchard et al. 2011; Bao and Zhang 2013; Zhang et al. 2014).
Although there is substantially less continuity in the composite rainfall Hovmöller diagram for the westerly flow regime studied here (Figs. 4b,d), modes with $c_{x} \sim 17 \mathrm{~m} \mathrm{~s}^{-1}$ are nevertheless readily apparent in full Hovmöller diagrams (Fig. 2) (cf. also Fig. 3 of Ichikawa and Yasunari 2007). This suggests that the explanation for the particular phase speed $c_{x} \sim$ $\pm 17 \mathrm{~m} \mathrm{~s}^{-1}$ transcends the unique background characteristics of the two regimes, although the background flow direction clearly plays a key role in determining their propagation direction (Ichikawa and Yasunari 2007).

What establishes the zonal gravity wave phase speed $c_{x} \sim \pm 17 \mathrm{~m} \mathrm{~s}^{-1}$ ? The intrinsic phase speed of this mode can be estimated from a suitable estimate of $U$ as $c_{i}=c_{x} \pm U$. Although establishing a representative value for $U$ is not straightforward, a range of possible values can be explored. For the easterly regime, a vertical mean from the upper troposphere can be assumed (i.e., $U \sim-8 \mathrm{~m} \mathrm{~s}^{-1}$ ), which would be consistent with an upper-tropospheric energy source (Fig. 7; Takayabu et al. 1996). Yet an upper-level average is clearly less relevant for the westerly regime, given that westerly flow is only found in the lower to midtroposphere (Figs. 3 and 4b,d). For the possibility that the lower- to midtropospheric flow is critical, we may consider massweighted averages from 850 to $400 \mathrm{hPa}: U \sim-5$ (easterly) and $3 \mathrm{~ms}^{-1}$ (westerly). Thus, we find the range $c_{i} \sim-9$ to $-12 \mathrm{~m} \mathrm{~s}^{-1}$ for easterly, and $c_{i} \sim$ $14 \mathrm{~m} \mathrm{~s}^{-1}$ for the westerly regime. We can then invoke these estimates of intrinsic phase speed to determine the implied vertical mode structure, from which direct comparison can be made with the model results. Using the dispersion relation for linear gravity waves (neglecting Coriolis effects), we may write $c_{i}=N / m$, where $N$ is the Brunt-Väisälä frequency and $m=2 \pi / \lambda_{z}$ (e.g., Rotunno 1983). Taking $N \sim 0.01 \mathrm{~s}^{-1}$, we find $\lambda_{z}=2 \pi c_{i} / N \sim 6-9 \mathrm{~km}$. This range of values is in approximate agreement with the tilted rays in $\theta_{v}^{*}$ and $u^{\prime}$ apparent in Fig. 7.

The phase speed $c_{x} \sim \pm 17 \mathrm{~m} \mathrm{~s}^{-1}$ noted here is similar to that of offshore-propagating diurnal gravity waves in the Panama Bight region (Mapes et al. 2003a,b; Warner et al. 2003), the Bay of Bengal (Yang and Slingo 2001; Zuidema 2003), and the South China Sea (Aves and Johnson 2008). Assuming this commonality is not coincidence, it supports the argument that this phase speed is determined by the vertical mode structure of the parent heating that forces it, via the relation between $c_{i}$ and $m$ noted above. This argument has strong support from past studies (Nicholls et al. 1991; Mapes 1993; Herman and Raymond 2014). From this argument, the phase speed in turn owes inherently to the vertical structure of the moist convection, as 
determined by the interaction between clouds and mesoscale circulation and their diurnal evolution (Zipser 1977; Houze et al. 1981; Mapes and Houze 1995; Houze 1997). Future work comparing the diurnal propagating modes in these distinct regions would be valuable for examining this. Furthermore, the potential influence of the strong vertical wind shear that appears prominently in the westerly regime needs to be explored (Fig. 3b; Tulich and Kiladis 2012).

Yet a unique feature of the MC may favor or amplify this specific gravity wave mode-namely, resonant interaction between Borneo and the Sumatra-Malay Peninsula region through diurnal phase locking. A clear characteristic of the diurnal modes in Fig. 4 is a zonal wavelength $\lambda_{x} \sim 1500 \mathrm{~km}$, which matches the zonal distance between the primary mesoscale convective systems of Sumatra and Borneo to first approximation (Fig. 6). With the phase speed of $c_{x} \sim \pm 17 \mathrm{~m} \mathrm{~s}^{-1}$, this mode propagates exactly this distance in one diurnal cycle, indicating that it is diurnally phase-locked. Hence, the synchronized diurnal variation of the Borneo and Sumatra convective systems, with compensating subsidence between them, serves as a robust periodic forcing function of fixed wavelength that may directly project onto this model (Figs. 6 and 8). Thus, we hypothesize that the phase locking of this gravity wave with these two diurnal convective systems enhances its amplitude and/or lifetime. Phase locking with the diurnal cycle has also been hypothesized to play a key role in the maintenance of synoptic-scale 2-day waves by Chen and Houze (1997) over the open ocean.

Furthermore, the background flow may indeed favor the potential for diurnally forced gravity waves to couple with convection over long horizontal distances. Qian et al. (2009) explored dry land-sea breeze theory (Rotunno 1983) with the addition of a constant background flow. They found that a background flow causes downwind tilt of the diurnally excited gravity waves, while Doppler shifting constricts the horizontal scale of the upwind wave packet and stretches the horizontal scale of the downwind packet. This Doppler shifting effect of background flow therefore enhances the potential for coupling between distant islands for the downwind-propagating gravity wave packet. Future studies with various levels of idealization would be valuable to assessing the role of diurnal phase locking between Borneo and Sumatra.

In addition to the zonally propagating gravity wave mode, a gravity wave coupled to the deep convection that propagates southwestward offshore from Sumatra has also been described (Figs. 9, 10, and 12) (Fujita et al. 2011; Love et al. 2011). In contrast to the zonally propagating mode, the propagation of this gravity wave cannot be clearly distinguished from that of the deep convection itself, which both propagate at a slower rate of $\sim 7-8 \mathrm{~m} \mathrm{~s}^{-1}$ (Love et al. 2011). The zonal motion of convective systems near Borneo also move at approximately this speed, which is indeed found to be consistent with that predicted from density current theory. Yet it remains unclear why the overriding zonally propagating gravity wave mode takes on a faster phase speed than the convection, while in the case of the southwestwardpropagating disturbance it does not. Whether or not this distinction owes to interaction the diurnal phase-locking mechanism described above is worth investigating; it seems clear that this mechanism would not apply to the southwestward-propagating mode of Sumatra.

\section{Summary and conclusions}

While rainfall in the Maritime Continent (MC) is primarily triggered by the local diurnal forcing agents tied to individual islands, a zonal Hovmöller view of rainfall often demonstrates a remarkable spatiotemporal continuity of rainfall across multiple islands and multiple diurnal cycles (Figs. 2 and 4). The propagation direction of these disturbances is strongly influenced by the MJO through its control over the background zonal wind (Ichikawa and Yasunari 2007). These disturbances have not been well documented, while their exact nature has remained elusive. Herein we have investigated these systems through a well-validated convection-permitting model simulation conducted during the time of the 2011/12 DYNAMO field campaign, which explicitly represents both convective processes and large-scale dynamics. The analysis has focused on the October 2011 MJO event.

The primary conclusions of this study are as follows: 1) the zonally propagating diurnal rainfall disturbances in the MC are the result of diurnally phase-locked gravity waves excited by and coupled with diurnal mesoscale convective systems; and 2) although these gravity waves become decoupled from convection outside of the $\mathrm{MC}$, their signature in divergent flow can be tracked over total distances exceeding $6000 \mathrm{~km}$. These gravity waves are excited by the vigorous, top-heavy nocturnal convective systems that develop over and offshore from both Borneo and Sumatra. Yet these gravity waves also appear to orchestrate new rainfall systems as they propagate at speeds faster than individual convective storms, similar to discrete propagation of diurnal rainfall documented previously (Mapes et al. 2003a; Pritchard et al. 2011; Bao and Zhang 2013). The diurnal phase locking of these modes can be understood as follows: their characteristic wavelength is $\sim 1500 \mathrm{~km}$, which approximately matches the zonal distance between Sumatra and Borneo; since their phase speed is approximately $\pm 17 \mathrm{~m} \mathrm{~s}^{-1}$, they propagate the distance of this gap in one diurnal cycle. 
The phase speed of these gravity waves is similar to that of diurnal offshore-propagating gravity waves investigated in the Panama Bight region (Mapes et al. 2003a,b; Warner et al. 2003), the Bay of Bengal (Yang and Slingo 2001; Zuidema 2003), and the South China Sea (Aves and Johnson 2008). This consistency may imply that the phase speed inherently owes to the vertical heating mode structure of the parent convection, which may in turn be similar among these regions. Future studies comparing this phenomenon across these distinct regions would be valuable to this subject.

We additionally hypothesize that the unique geography of the MC favors or amplifies this specific gravity wave mode owing to its diurnal phase locking with the synchronized diurnal cycles of Borneo and Sumatra. Namely, given the diurnal phase locking noted above due to the ideal phase speed and the close match of zonal separation between these islands with the wavelength of this gravity wave mode, it may experience maintenance not only through the individual convective forcing of one island, but that of both islands. Future idealized model experiments will be valuable to assessing the potential role of this resonant feedback from diurnal phase locking.

Future work will also be valuable to understanding why a distinct southwestward-propagating gravity wave mode that couples to offshore-propagating convection from Sumatra is characterized by a distinctly slower phase speed of $\sim 7 \mathrm{~m} \mathrm{~s}^{-1}$, that is, such that its propagation is indistinguishable from that of the convection itself. This is in contrast to the zonally propagating gravity wave mode, which propagates substantially faster than individual convective systems, and hence favors discrete propagation. A more comprehensive understanding of the sensitivity of diurnal gravity waves to both the background flow strength and state and to the unique island geography of the MC will be of great value to this area of research.

Acknowledgments. We gratefully acknowledge funding from National Science Foundation Grant 1712290 and Department of Energy Grant WACCEM subcontracted through PNNL. We also thank Yue (Michael) Ying for providing WRF postprocessing code and Sourav Taraphdar for making model output available to us. We thank Xingchao Chen for insightful discussions on this work. We are very grateful to George Kiladis and an anonymous reviewer for their thoughtful comments on the study, which substantially improved its clarity. Computational resources for this work were provided by the Texas Advanced Computing Center (TACC) at The University of Texas at Austin. The model output used in this study is archived in TACC storage, and is available for community use upon request. TRMM data were retrieved from https://pmm.nasa.gov/data-access/downloads/trmm, and ERA5 data from the Copernicus Climate Change Service Climate Data Store (https://cds.climate.copernicus.eu/).

\section{REFERENCES}

Aves, S., and R. H. Johnson, 2008: The diurnal cycle of convection over the northern South China Sea. J. Meteor. Soc. Japan, 86, 919-934, https://doi.org/10.2151/jmsj.86.919.

Bao, X., and F. Zhang, 2013: Impacts of the mountain-plains solenoid and cold pool dynamics on the diurnal variation of warm-season precipitation over northern China. Atmos. Chem. Phys., 13, 69656982, https://doi.org/10.5194/acp-13-6965-2013.

Bhatt, B. C., S. Sobolowski, and A. Higuchi, 2016: Simulation of diurnal rainfall variability over the Maritime Continent with a high-resolution regional climate model. J. Meteor. Soc. Japan, 94A, 89-103, https://doi.org/10.2151/jmsj.2015-052.

Chen, S. S., and R. A. Houze, 1997: Diurnal variation and life-cycle of deep convective systems over the tropical pacific warm pool. Quart. J. Roy. Meteor. Soc., 123, 357-388, https://doi.org/ 10.1002/qj.49712353806.

Chen, X., and F. Zhang, 2019: Relative roles of preconditioning moistening and global circumnavigating mode on the MJO convective initiation during DYNAMO. Geophys. Res. Lett., 46, 1079-1087, https://doi.org/10.1029/2018GL080987.

—, O. M. Pauluis, and F. Zhang, 2018: Atmospheric overturning across multiple scales of an MJO event during the CINDY/DYNAMO campaign. J. Atmos. Sci., 75, 381-399, https://doi.org/10.1175/JAS-D-17-0060.1.

_, F. Zhang, and J. H. Ruppert, 2019: Modulations of the diurnal cycle of coastal rainfall over South China caused by the boreal summer intraseasonal oscillation. J. Climate, 32, 2089-2108, https://doi.org/10.1175/JCLI-D-18-0786.1.

Cronin, T. W., K. A. Emanuel, and P. Molnar, 2015: Island precipitation enhancement and the diurnal cycle in radiative-convective equilibrium. Quart. J. Roy. Meteor. Soc., 141, 1017-1034, https:// doi.org/10.1002/qj.2443.

Dai, A., 2001: Global precipitation and thunderstorm frequencies. Part II: Diurnal variations. J. Climate, 14, 1112-1128, https://doi.org/10.1175/1520-0442(2001)014<1112:GPATFP $>$ 2.0.CO;2.

—, and K. E. Trenberth, 2004: The diurnal cycle and its depiction in the Community Climate System Model. J. Climate, 17, 930-951, https://doi.org/10.1175/1520-0442(2004) 017<0930:TDCAID > 2.0.CO;2.

Dee, D. P., and Coauthors, 2011: The ERA-Interim reanalysis: Configuration and performance of the data assimilation system. Quart. J. Roy. Meteor. Soc., 137, 553-597, https://doi.org/ 10.1002/qj.828.

DeMott, C. A., B. O. Wolding, E. D. Maloney, and D. A. Randall, 2018: Atmospheric mechanisms for MJO decay over the Maritime Continent. J. Geophys. Res. Atmos., 123, 5188-5204, https://doi.org/10.1029/2017JD026979.

Feng, J., T. Li, and W. Zhu, 2015: Propagating and nonpropagating MJO events over Maritime Continent. J. Climate, 28, 84308449, https://doi.org/10.1175/JCLI-D-15-0085.1.

Fujita, M., K. Yuneyama, S. Mori, T. Nasuno, and M. Satoh, 2011: Diurnal convection peaks over the eastern Indian Ocean off Sumatra during different MJO phases. J. Meteor. Soc. Japan, 89A, 317-330, https://doi.org/10.2151/jmsj.2011-A22.

Gonzalez, A. O., and X. Jiang, 2017: Winter mean lower tropospheric moisture over the Maritime Continent as a climate 
model diagnostic metric for the propagation of the MaddenJulian oscillation. Geophys. Res. Lett., 44, 2588-2596, https:// doi.org/10.1002/2016GL072430.

Gottschalck, J., P. E. Roundy, C. J. Schreck III, A. Vintzileos, and C. Zhang, 2013: Large-scale atmospheric and oceanic conditions during the 2011-12 DYNAMO field campaign. Mon. Wea. Rev., 141, 4173-4196, https://doi.org/10.1175/MWR-D-13-00022.1.

Haertel, P. T., and G. N. Kiladis, 2004: Dynamics of 2-day equatorial waves. J. Atmos. Sci., 61, 2707-2721, https://doi.org/ 10.1175/JAS3352.1.

Herman, M. J., and D. J. Raymond, 2014: WTG cloud modeling with spectral decomposition of heating. J. Adv. Model. Earth Syst., 6, 1121-1140, https://doi.org/10.1002/2014MS000359.

Holloway, C. E., S. J. Woolnough, and G. M. S. Lister, 2012: Precipitation distributions for explicit versus parametrized convection in a large-domain high-resolution tropical case study. Quart. J. Roy. Meteor. Soc., 138, 1692-1708, https://doi.org/10.1002/qj.1903.

Houze, R. A., Jr., 1997: Stratiform precipitation in regions of convection: A meteorological paradox? Bull. Amer. Meteor. Soc., 78, 2179-2196, https://doi.org/10.1175/1520-0477(1997) $078<2179$ :SPIROC $>2.0 . \mathrm{CO} ; 2$.

— S. G. Geotis, F. D. Marks, and A. K. West, 1981: Winter monsoon convection in the vicinity of North Borneo. Part I: Structure and time variation of the clouds and precipitation. Mon. Wea. Rev., 109, 1595-1614, https://doi.org/10.1175/15200493(1981)109<1595:WMCITV > 2.0.CO;2.

Huffman, G. J., and Coauthors, 2007: The TRMM Multisatellite Precipitation Analysis (TMPA): Quasi-global, multiyear, combinedsensor precipitation estimates at fine scales. J. Hydrometeor., 8, 38-55, https://doi.org/10.1175/JHM560.1.

Ichikawa, H., and T. Yasunari, 2006: Time-space characteristics of diurnal rainfall over Borneo and surrounding oceans as observed by TRMM-PR. J. Climate, 19, 1238-1260, https:// doi.org/10.1175/JCLI3714.1.

— , and - 2007: Propagating diurnal disturbances embedded in the Madden-Julian oscillation. Geophys. Res. Lett., 34, L18811, https://doi.org/10.1029/2007GL030480.

Jiang, X., 2017: Key processes for the eastward propagation of the Madden-Julian oscillation based on multimodel simulations. J. Geophys. Res. Atmos., 122, 755-770, https://doi.org/10.1002/ 2016JD025955.

—_, and Coauthors, 2009: Vertical heating structures associated with the MJO as characterized by TRMM estimates, ECMWF reanalyses, and forecasts: A case study during 1998/99 winter. J. Climate, 22, 6001-6020, https://doi.org/ 10.1175/2009JCLI3048.1.

Johnson, R. H., 1982: Vertical motion in near-equatorial winter monsoon convection. J. Meteor. Soc. Japan, 60, 682-690, https://doi.org/10.2151/jmsj1965.60.2_682.

_ , and D. L. Priegnitz, 1981: Winter monsoon convection in the vicinity of North Borneo. Part II: Effects on large-scale fields. Mon. Wea. Rev., 109, 1615-1628, https://doi.org/10.1175/15200493(1981)109<1615:WMCITV>2.0.CO;2.

— , and D. C. Kriete, 1982: Thermodynamic and circulation characteristics, of winter monsoon tropical mesoscale convection. Mon. Wea. Rev., 110, 1898-1911, https://doi.org/ 10.1175/1520-0493(1982)110<1898:TACCOW >2.0.CO;2.

_- , and P. E. Ciesielski, 2013: Structure and properties of Madden-Julian oscillations deduced from DYNAMO sounding arrays. J. Atmos. Sci., 70, 3157-3179, https:// doi.org/10.1175/JAS-D-13-065.1.

,,-- J. H. Ruppert, and M. Katsumata, 2015: Soundingbased thermodynamic budgets for DYNAMO. J. Atmos. Sci., 72, 598-622, https://doi.org/10.1175/JAS-D-14-0202.1.
Kerns, B. W., and S. S. Chen, 2016: Large-scale precipitation tracking and the MJO over the Maritime Continent and Indo-Pacific warm pool. J. Geophys. Res. Atmos., 121, 87558776, https://doi.org/10.1002/2015JD024661.

Kiladis, G. N., K. H. Straub, and P. T. Haertel, 2005: Zonal and vertical structure of the Madden-Julian oscillation. J. Atmos. Sci., 62, 2790-2809, https://doi.org/10.1175/JAS3520.1.

—, M. C. Wheeler, P. T. Haertel, K. H. Straub, and P. E. Roundy, 2009: Convectively coupled equatorial waves. Rev. Geophys., 47, RG2003, https://doi.org/10.1029/2008RG000266.

Kim, D., H. Kim, and M.-I. Lee, 2017: Why does the MJO detour the Maritime Continent during austral summer? Geophys. Res. Lett., 44, 2579-2587, https://doi.org/10.1002/ 2017 GL072643.

Krishnamurti, T. N., M. Kanamitsu, W. J. Koss, and J. D. Lee, 1973: Tropical east-west circulations during the northern winter. J. Atmos. Sci., 30, 780-787, https://doi.org/10.1175/15200469(1973)030<0780:TECDTN $>2.0$. CO;2.

Love, B. S., A. J. Matthews, and G. M. S. Lister, 2011: The diurnal cycle of precipitation over the Maritime Continent in a highresolution atmospheric model. Quart. J. Roy. Meteor. Soc., 137, 934-947, https://doi.org/10.1002/qj.809.

Madden, R. A., and P. R. Julian, 1972: Description of global-scale circulation cells in the tropics with a 40-50 day period. J. Atmos. Sci., 29, 1109-1123, https://doi.org/10.1175/15200469(1972)029<1109:DOGSCC >2.0.CO;2.

Mapes, B. E., 1993: Gregarious tropical convection. J. Atmos. Sci., 50, 2026-2037, https://doi.org/10.1175/1520-0469(1993) $050<2026$ :GTC $>2.0 . \mathrm{CO} ; 2$.

_ , and R. A. Houze Jr., 1995: Diabatic divergence profiles in western Pacific mesoscale convective systems. J. Atmos. Sci., 52, 1807-1828, https://doi.org/10.1175/1520-0469(1995)052<1807: DDPIWP $>2.0 . \mathrm{CO} ; 2$.

— T. T. Warner, M. Xu, and A. J. Negri, 2003a: Diurnal patterns of rainfall in northwestern South America. Part I: Observations and context. Mon. Wea. Rev., 131, 799-812, https://doi.org/ 10.1175/1520-0493(2003)131<0799:DPORIN > 2.0.CO;2.

, ——, and — 2003b: Diurnal patterns of rainfall in northwestern South America. Part III: Diurnal gravity waves and nocturnal convection offshore. Mon. Wea. Rev., 131, 830-844, https://doi.org/10.1175/1520-0493(2003)131<0830: DPORIN $>2.0 . \mathrm{CO} ; 2$.

Markowski, P., and Y. Richardson, 2010: Mesoscale Meteorology in Midlatitudes. John Wiley and Sons, 430 pp., https://doi.org/ 10.1002/9780470682104.

Neale, R., and J. Slingo, 2003: The Maritime Continent and its role in the global climate: A GCM study. J. Climate, 16, 834-848, https:// doi.org/10.1175/1520-0442(2003)016<0834:TMCAIR>2.0.CO;2.

Nicholls, M. E., R. A. Pielke, and W. R. Cotton, 1991: Thermally forced gravity waves in an atmosphere at rest. J. Atmos. Sci., 48, 1869-1884, https://doi.org/10.1175/1520-0469(1991) 048<1869:TFGWIA > 2.0.CO;2.

Oh, J.-H., K.-Y. Kim, and G.-H. Lim, 2012: Impact of MJO on the diurnal cycle of rainfall over the western Maritime Continent in the austral summer. Climate Dyn., 38, 1167-1180, https:// doi.org/10.1007/s00382-011-1237-4.

Peatman, S. C., A. J. Matthews, and D. P. Stevens, 2014: Propagation of the Madden-Julian oscillation through the Maritime Continent and scale interaction with the diurnal cycle of precipitation. Quart. J. Roy. Meteor. Soc., 140, 814-825, https:// doi.org/10.1002/qj.2161.

Powell, S. W., and R. A. Houze Jr., 2013: The cloud population and onset of the Madden-Julian oscillation over the Indian Ocean 
during DYNAMO-AMIE. J. Geophys. Res. Atmos., 118 , 11 979-11 995, https://doi.org/10.1002/2013JD020421.

$\longrightarrow$, and - 2015: Effect of dry large-scale vertical motions on initial MJO convective onset. J. Geophys. Res. Atmos., 120, 4783-4805, https://doi.org/10.1002/2014JD022961.

Pritchard, M. S., M. W. Moncrieff, and R. C. J. Somerville, 2011: Orogenic propagating precipitation systems over the United States in a Global climate model with embedded explicit convection. J. Atmos. Sci., 68, 1821-1840, https://doi.org/10.1175/ 2011JAS3699.1.

Qian, T., C. C. Epifanio, and F. Zhang, 2009: Linear theory calculations for the sea breeze in a background wind: The equatorial case. J. Atmos. Sci., 66, 1749-1763, https:// doi.org/10.1175/2008JAS2851.1.

,$- \ldots$, and — 2012: Topographic effects on the tropical land and sea breeze. J. Atmos. Sci., 69, 130-149, https://doi.org/ 10.1175/JAS-D-11-011.1.

Ramage, C. S., 1968: Role of a tropical "Maritime Continent" in the atmospheric circulation. Mon. Wea. Rev., 96, 365-370, https:// doi.org/10.1175/1520-0493(1968)096<0365:ROATMC >2.0.CO;2.

Rauniyar, S. P., and K. J. E. Walsh, 2011: Scale interaction of the diurnal cycle of rainfall over the Maritime Continent and Australia: Influence of the MJO. J. Climate, 24, 325-348, https://doi.org/10.1175/2010JCLI3673.1.

Rotunno, R., 1983: On the linear theory of the land and sea breeze. J. Atmos. Sci., 40, 1999-2009, https://doi.org/10.1175/15200469(1983)040<1999:OTLTOT>2.0.CO;2.

Ruppert, J. H., 2016: Diurnal timescale feedbacks in the tropical cumulus regime. J. Adv. Model. Earth Syst., 8, 1483-1500, https://doi.org/10.1002/2016MS000713.

_ , and R. H. Johnson, 2015: Diurnally modulated cumulus moistening in the preonset stage of the Madden-Julian oscillation during DYNAMO. J. Atmos. Sci., 72, 1622-1647, https:// doi.org/10.1175/JAS-D-14-0218.1.

— ical warm pool. J. Adv. Model. Earth Syst., 8, 669-690, https:// doi.org/10.1002/2015MS000610.

__ , and C. Hohenegger, 2018: Diurnal circulation adjustment and organized deep convection. J. Climate, 31, 4899-4916, https:// doi.org/10.1175/JCLI-D-17-0693.1.

_ , and D. Klocke, 2019: The two diurnal modes of tropical upward motion. Geophys. Res. Lett., 46, 2911-2921, https:// doi.org/10.1029/2018GL081806.

Sakaeda, N., G. Kiladis, and J. Dias, 2017: The diurnal cycle of tropical cloudiness and rainfall associated with the MaddenJulian oscillation. J. Climate, 30, 3999-4020, https://doi.org/ 10.1175/JCLI-D-16-0788.1.

Skamarock, W. C., and Coauthors, 2008: A description of the Advanced Research WRF version 3. NCAR Tech. Note NCAR/ TN-475+STR, 113 pp., https://doi.org/10.5065/D68S4MVH.

Takayabu, Y. N., K.-M. Lau, and C.-H. Sui, 1996: Observation of a quasi-2-day wave during TOGA COARE. Mon. Wea. Rev., 124, 1892-1913, https://doi.org/10.1175/1520-0493(1996) 124<1892:OOAQDW>2.0.CO;2.

Tulich, S. N., and G. N. Kiladis, 2012: Squall lines and convectively coupled gravity waves in the tropics: Why do most cloud systems propagate westward? J. Atmos. Sci., 69, 29953012, https://doi.org/10.1175/JAS-D-11-0297.1.

Waliser, D. E., K. M. Lau, W. Stern, and C. Jones, 2003: Potential predictability of the Madden-Julian oscillation. Bull. Amer. Meteor. Soc., 84, 33-50, https://doi.org/10.1175/BAMS-84-1-33.

Wang, S., A. H. Sobel, F. Zhang, Y. Q. Sun, Y. Yue, and L. Zhou, 2015: Regional simulation of the October and November
MJO events observed during the CINDY/DYNAMO field campaign at gray zone resolution. J. Climate, 28, 2097-2119, https://doi.org/10.1175/JCLI-D-14-00294.1.

Warner, T. T., B. E. Mapes, and M. Xu, 2003: Diurnal patterns of rainfall in northwestern South America. Part II: Model simulations. Mon. Wea. Rev., 131, 813-829, https://doi.org/ 10.1175/1520-0493(2003)131<0813:DPORIN > 2.0.CO;2.

Wheeler, M., and H. Nguyen, 2015: Equatorial waves. Encyclopedia of Atmospheric Sciences, 2nd ed. J. Pyle and F. Zhang, Eds., Vol. 6, Elsevier, 102-112, https://doi.org/10.1016/B978-012-382225-3.00414-X

Yamanaka, M. D., S.-Y. Ogino, P.-M. Wu, J.-I. Hamada, S. Mori, J. Matsumoto, and F. Syamsudin, 2018: Maritime continent coastlines controlling Earth's climate. Prog. Earth Planet. Sci., 5, 21, https://doi.org/10.1186/s40645-018-0174-9.

Yanai, M., S. Esbensen, and J.-H. Chu, 1973: Determination of bulk properties of tropical cloud clusters from large-scale heat and moisture budgets. J. Atmos. Sci., 30, 611-627, https://doi.org/ 10.1175/1520-0469(1973)030<0611:DOBPOT>2.0.CO;2.

Yang, G.-Y., and J. Slingo, 2001: The diurnal cycle in the tropics. Mon. Wea. Rev., 129, 784-801, https://doi.org/ 10.1175/1520-0493(2001)129<0784:TDCITT>2.0.CO;2.

Ying, Y., and F. Zhang, 2017: Practical and intrinsic predictability of multiscale weather and convectively coupled equatorial waves during the active phase of an MJO. J. Atmos. Sci., 74, 3771-3785, https://doi.org/10.1175/JAS-D-17-0157.1.

Yoneyama, K., C. Zhang, and C. N. Long, 2013: Tracking pulses of the Madden-Julian oscillation. Bull. Amer. Meteor. Soc., 94, 1871-1891, https://doi.org/10.1175/BAMS-D-12-00157.1.

Yu, H., R. H. Johnson, P. E. Ciesielski, and H.-C. Kuo, 2018: Observation of quasi-2-day convective disturbances in the equatorial Indian Ocean during DYNAMO.J. Atmos. Sci., 75, 2867-2888, https://doi.org/10.1175/JAS-D-17-0351.1.

Zeng, X., and A. Beljaars, 2005: A prognostic scheme of sea surface skin temperature for modeling and data assimilation. Geophys. Res. Lett., 32, L14605, https://doi.org/ 10.1029/2005GL023030.

Zhang, C., 2005: Madden-Julian oscillation. Rev. Geophys., 43, RG2003, https://doi.org/10.1029/2004RG000158.

, and J. Ling, 2017: Barrier effect of the Indo-Pacific Maritime Continent on the MJO: Perspectives from tracking MJO precipitation. J. Climate, 30, 3439-3459, https://doi.org/ 10.1175/JCLI-D-16-0614.1.

Zhang, F., S. Taraphdar, and S. Wang, 2017: The role of global circumnavigating mode in the MJO initiation and propagation. J. Geophys. Res. Atmos., 122, 5837-5856, https://doi.org/ 10.1002/2016JD025665.

Zhang, Y., F. Zhang, and J. Sun, 2014: Comparison of the diurnal variations of warm-season precipitation for East Asia vs. North America downstream of the Tibetan Plateau vs. the Rocky Mountains. Atmos. Chem. Phys., 14, 10 741-10759, https://doi.org/10.5194/acp-14-10741-2014.

Zipser, E. J., 1977: Mesoscale and convective-scale downdrafts as distinct components of squall-line structure. Mon. Wea. Rev., 105, 1568-1589, https://doi.org/10.1175/1520-0493(1977) $105<1568$ :MACDAD $>2.0$.CO;2.

Zuidema, P., 2003: Convective clouds over the Bay of Bengal. Mon. Wea. Rev., 131, 780-798, https://doi.org/10.1175/15200493(2003)131<0780:CCOTBO > 2.0.CO;2.

Zuluaga, M. D., and R. A. Houze, 2013: Evolution of the population of precipitating convective systems over the equatorial Indian Ocean in active phases of the Madden-Julian oscillation. J. Atmos. Sci., 70, 2713-2725, https://doi.org/10.1175/JAS-D-12-0311.1. 